\title{
Influence of Constitution and Charge on Radical Pairing Interactions in Tris-radical Tricationic Complexes
}

\author{
Chuyang Cheng, ${ }^{\dagger}$ Tao Cheng, ${ }^{\S}$ Hai Xiao, ${ }^{\S}$ Matthew D. Krzyaniak, ${ }^{\dagger \neq}$ Yuping Wang, ${ }^{\dagger}$
}

Paul R. McGonigal, ${ }^{\dagger, \|}$ Marco Frasconi, ${ }^{\dagger, \perp}$ Jonathan C. Barnes, ${ }^{\dagger, \#}$ Albert C. Fahrenbach, ${ }^{\dagger, \otimes, \nabla}$

Michael R. Wasielewski, ${ }^{\dagger,+}$ William A. Goddard III, ${ }^{\S}$ and J. Fraser Stoddart*, ${ }^{\dagger}$

${ }^{\dagger}$ Department of Chemistry, Northwestern University, 2145 Sheridan Road, Evanston, Illinois 60208, United States

${ }^{\S}$ Materials and Process Simulation Center (MC 139-74), California Institute of Technology, Pasadena, California 91125, United States

${ }^{\ddagger}$ Argonne-Northwestern Solar Energy Research (ANSER) Center, Northwestern University, 2145 Sheridan Road, Evanston, Illinois 60208, United States

"Department of Chemistry, Durham University, South Road, Durham DH1 3LE, United Kingdom

${ }^{\perp}$ Department of Chemical Sciences, University of Padova, Via Marzolo 1, Padova 35131, Italy

\# Department of Chemistry, Massachusetts Institute of Technology, 77 Massachusetts Avenue, Cambridge, Massachusetts 02139, United States

${ }^{\otimes}$ Department of Molecular Biology and Center for Computational and Integrative Biology, Massachusetts General Hospital, Howard Hughes Medical Institute, 185 Cambridge Street, Boston, Massachusetts 02114, United States

${ }^{\nabla}$ Earth-Life Science Institute, Tokyo Institute of Technology, 2-12-1-IE-1 Ookayama, Meguro-ku, Tokyo 152-8550, Japan

Supporting Information

\begin{abstract}
The results of a systematic investigation of trisradical tricationic complexes formed between cyclobis(paraquat-p-phenylene) bisradical dicationic $\left(\mathrm{CBPQT}^{2(\bullet+)}\right)$ rings and a series of 18 dumbbells, containing centrally located 4,4'-bipyridinium radical cationic $\left(\mathrm{BIPY}^{\bullet+}\right)$ units within oligomethylene chains terminated for the most part by charged 3,5-dimethylpyridinium $\left(\mathrm{PY}^{+}\right)$and/or neutral 3,5dimethylphenyl $(\mathrm{PH})$ groups, are reported. The complexes were obtained by treating equimolar amounts of the CBPQT ${ }^{4+}$
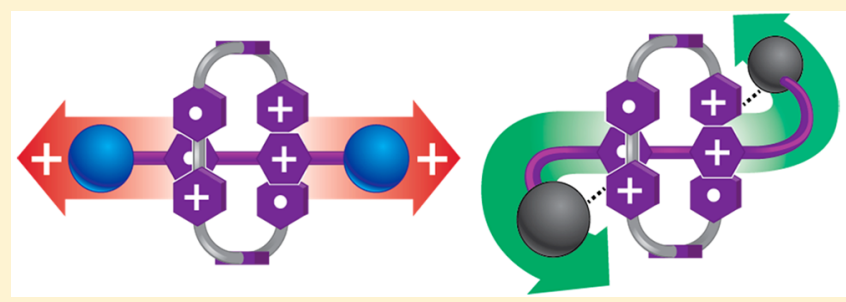
ring and the dumbbells containing BIPY ${ }^{2+}$ units with zinc dust in acetonitrile solutions. Whereas UV-Vis-NIR spectra revealed absorption bands centered on ca. $1100 \mathrm{~nm}$ with quite different intensities for the 1:1 complexes depending on the constitutions and charges on the dumbbells, titration experiments showed that the association constants $\left(K_{\mathrm{a}}\right)$ for complex formation vary over a wide range, from $800 \mathrm{M}^{-1}$ for the weakest to $180000 \mathrm{M}^{-1}$ for the strongest. While Coulombic repulsions emanating from PY groups located at the ends of some of the dumbbells undoubtedly contribute to the destabilization of the trisradical tricationic complexes, solid-state superstructures support the contention that those dumbbells with neutral PH groups at the ends of flexible and appropriately constituted links to the $\mathrm{BIPY}^{\bullet+}$ units stand to gain some additional stabilization from $\mathrm{C}-\mathrm{H} \cdots \pi$ interactions between the $\mathrm{CBPQT}^{2(\bullet)}$ rings and the $\mathrm{PH}$ termini on the dumbbells. The findings reported in this Article demonstrate how structural changes implemented remotely from the BIPY ${ }^{\bullet+}$ units influence their non-covalent bonding interactions with $\mathrm{CBPQT}^{2(\bullet+)}$ rings. Different secondary effects (Coulombic repulsions versus $\mathrm{C}-\mathrm{H} \cdots \pi$ interactions) are uncovered, and their contributions to both binding strengths associated with trisradical interactions and the kinetics of associations and dissociations are discussed at some length, supported by extensive DFT calculations at the M06-D3 level. A fundamental understanding of molecular recognition in radical complexes has relevance when it comes to the design and synthesis of non-equilibrium systems.
\end{abstract}

\section{INTRODUCTION}

Non-covalent bonding interactions have become an important consideration, along with molecular recognition, when designing functional materials during the past couple of decades. ${ }^{1}$ The bottom-up approach of supramolecular chemistry ${ }^{2}$ has contributed to many areas, with potential for applications such as chemical sensors, ${ }^{3}$ responsive materials, ${ }^{4}$ drug delivery vehicles, ${ }^{5}$ catalysis, ${ }^{6}$ etc. Weak interactions such as hydrogen bonding, ${ }^{7}$ metal coordination, ${ }^{8}$ hydrophobic forces, ${ }^{9}$ van der Waals interactions, ${ }^{10} \pi-\pi$ stacking, ${ }^{11}$ and electrostatic effects ${ }^{12}$ have all been investigated widely in the context of supramolecular systems. Radical-radical interactions, however, have received only limited attention ${ }^{13}$ in such systems.

Received: May 5, 2016

Published: June 6, 2016 


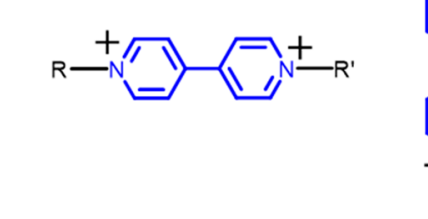

III

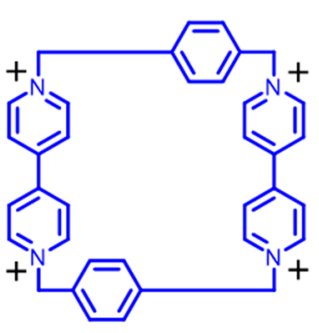

III

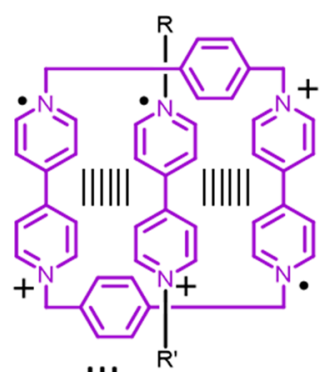

III

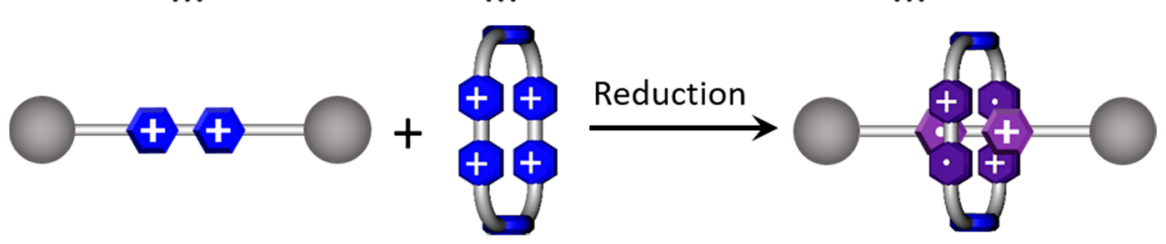

Figure 1. Structural formulas and graphical representations of $1,1^{\prime}$-dialkyl-4,4'-bipyridinium (BIPY $\left.{ }^{2+}\right)$ and cyclobis(paraquat-p-phenylene) $\left(\mathrm{CBPQT}^{4+}\right)$ leading, on reduction, to the formation of the $1: 1$ trisradical tricationic inclusion complex $\mathrm{BIPY}^{\bullet+} \mathrm{CCBPQT}^{2\left({ }^{\bullet+}\right)}$.

1,1'-Dialkyl-4,4'-bipyridinium (BIPY $\left.{ }^{2+}\right)$ dications are commonly used units ${ }^{14}$ in supramolecular chemistry, mostly as $\pi$ electron-poor acceptors in $\pi-\pi$ stacking, and in host-guest complexes. By contrast, the radical-radical dimerization of the reduced form of $\mathrm{BIPY}^{2+}$-namely $\mathrm{BIPY}^{\bullet+}$ - was discovered ${ }^{15}$ much earlier than the charge-transfer complexation ${ }^{16}$ of BIPY ${ }^{2+}$ dications with electron donors. The radical-radical dimerization $^{17}$ of BIPY ${ }^{\bullet+}$ radical cations, also known as pimerization, ${ }^{18}$ however, was not widely employed ${ }^{19}$ in the design of supramolecular systems because of the low binding ability ${ }^{17 a, b, d}$ of radical pairs, resulting in pimerization only being observable at significantly high concentrations. Cyclobis(paraquat- $p$ phenylene $)^{20}\left(\mathrm{CBPQT}^{4+}\right)$ as a higher homologue of $\mathrm{BIPY}^{2+}$, containing two $\mathrm{BIPY}^{2+}$ units connected in a rigid fashion by two para-xylylene linkers, has been exploited as an electrondeficient host ${ }^{20 c, 21}$ during the past quarter century. Recently, we discovered (Figure 1) that BIPY $^{2+}$ forms a trisradical tricationic complex ${ }^{22}$-namely $\mathrm{BIPY}^{\bullet+} \mathrm{CCBPQT}^{2(\bullet+)}$ - with the $\mathrm{CBPQT}^{4+}$ ring under reducing conditions. The binding constant $^{23}\left(K_{\mathrm{a}} \approx 10^{4} \mathrm{M}^{-1}\right.$ in $\left.\mathrm{MeCN}\right)$ associated with this 1:1 complex is comparable or even stronger than those $\left(K_{\mathrm{a}}=10^{3}-\right.$ $10^{5} \mathrm{M}^{-1}$ in $\left.\mathrm{MeCN}\right)$ involving donor-acceptor complexes ${ }^{24}$ between aromatic crown ethers and $\mathrm{CBPQT}^{4+}$. The strength of the trisradical tricationic complex is greater than that $\left(K_{\mathrm{a}}<10^{3}\right.$ $\mathrm{M}^{-1}$ in MeCN) involving dimerization ${ }^{15 e}$ of $\mathrm{BIPY}^{\circ+}$ units on account of the macrocyclic effect. ${ }^{25}$ Subsequently, we have introduced radical-radical interactions into templating the synthesis of rotaxanes ${ }^{26}$ and catanenes, ${ }^{27}$ as well as into foldamers ${ }^{28}$ daisy chains, ${ }^{29}$ molecular switches, ${ }^{30}$ molecular motors, ${ }^{31}$ molecular pumps, ${ }^{32}$ and semiconducting materials. ${ }^{33}$

Although there are a large number of molecular recognition motifs from which to choose when designing artificial molecular machines, ${ }^{31 \mathrm{~b}}$ there are few, if any, that can be switched back and forth between repulsion and attraction without making and breaking covalent bonds, while also being orthogonal/complementary to other common nonbonded interactions. Our recent study ${ }^{31,32}$ has revealed that not only are the radical-radical interactions between $\mathrm{BIPY}^{\circ+}$ units and $\mathrm{CBPQT}^{2(\bullet+)}$ rings capable of meeting the above criteria but also, more importantly, the kinetics of association and dissociation can be modulated, a key factor in designing nonequilibrium systems. In this Article, an in-depth investigation brings to light a simple way of modulating the thermodynamics of the trisradical interactions. We assess the binding aptitudes of the $\mathrm{CBPQT}^{2(\bullet+)}$ ring toward a series of dumbbells (Table 1 ) in which oligomethylene chains incorporate $\mathrm{BIPY}^{\circ+}$ units in their midriffs and carry variously (i) two positively charged 3,5dimethylpyridinium $\left(\mathrm{PY}^{+}\right)$termini, (ii) two neutral 3,5dimethylphenyl $(\mathrm{PH})$ termini, and (iii) a $\mathrm{PY}^{+}$terminus at one end and a PH terminus at the other, in addition to controls with (iv) only one $\mathrm{PY}^{+}$terminus and (v) no $\mathrm{PY}^{+}$or $\mathrm{PH}$ termini. We demonstrate that these $\mathrm{PY}^{+}$and $\mathrm{PH}$ termini, together with lengths from 0 to 12 methylene units separating them from the centrally located $\mathrm{BIPY}^{\bullet+}$ units, influence significantly the strengths of their trisradical tricationic complexes with the $\mathrm{CBPQT}^{2(\bullet+)}$ ring. Both (i) the number of $\mathrm{PY}^{+}$termini and (ii) the number of methylene groups between the positively charged $\mathrm{PY}^{+}$termini and the $\mathrm{BIPY}^{\circ+}$ units influence the stability of the trisradical tricationic complexes formed between these $\mathrm{BIPY}^{*+}$ units and the $\mathrm{CBPQT}^{2\left(\boldsymbol{\bullet}^{+}\right)}$ring. Doubling the number of $\mathrm{PY}^{+}$termini, as well as curtailing the number of methylene groups, decreases the strength of the complexes. By contrast, introducing electron-rich $\mathrm{PH}$ units in the vicinity of the trisradical tricationic midriffs leads to much stronger radicalpairing interactions. Experimental results and quantum mechanical $(\mathrm{QM})$ calculations reveal that additional $\mathrm{C}-\mathrm{H} \cdots \pi$ interactions exist in some of the trisradical tricationic complexes, i.e., the binding between the $\mathrm{CBPQT}^{2(\bullet+)}$ rings and the BIPY ${ }^{\circ+}$ units in the dumbbells can be enhanced by introducing $\pi$-electron-rich functions at appropriate positions. Data have been collected for the interactions of 18 different $\mathrm{BIPY}^{\bullet+}$ dumbbells with the $\mathrm{CBPQT}^{(\bullet+)}$ rings using (i) ultraviolet-visible-near-infrared (UV-Vis-NIR) spectroscopies and (ii) single-crystal X-ray diffraction (XRD), supported by (iii) density functional theory (DFT) calculations as well as (iv) cyclic voltammetry $(\mathrm{CV})$.

\section{RESULTS AND DISCUSSION}

Design Strategies and Syntheses. Recently, we have shown ${ }^{34}$ that Coulombic forces can change significantly the kinetic barriers associated with the threading of $\mathrm{CBPQT}^{4+} /$ $\mathrm{CBPQT}^{2(\bullet+)}$ rings onto both charged and neutral dumbbells. In this investigation, we explore the influence of Coulombic forces on the thermodynamics of pseudorotaxane formation. The $1,1^{\prime}$ didodecyl-4,4'-bipyridinium dication $\left(\mathrm{DB}^{2+}\right)$ was chosen as the standard viologen recognition counterpart for the 
Table 1. Structural Formulas and Corresponding Graphical Representations of the 18 Compounds $\mathrm{DB}^{2+}-\mathrm{DB}^{2+}$

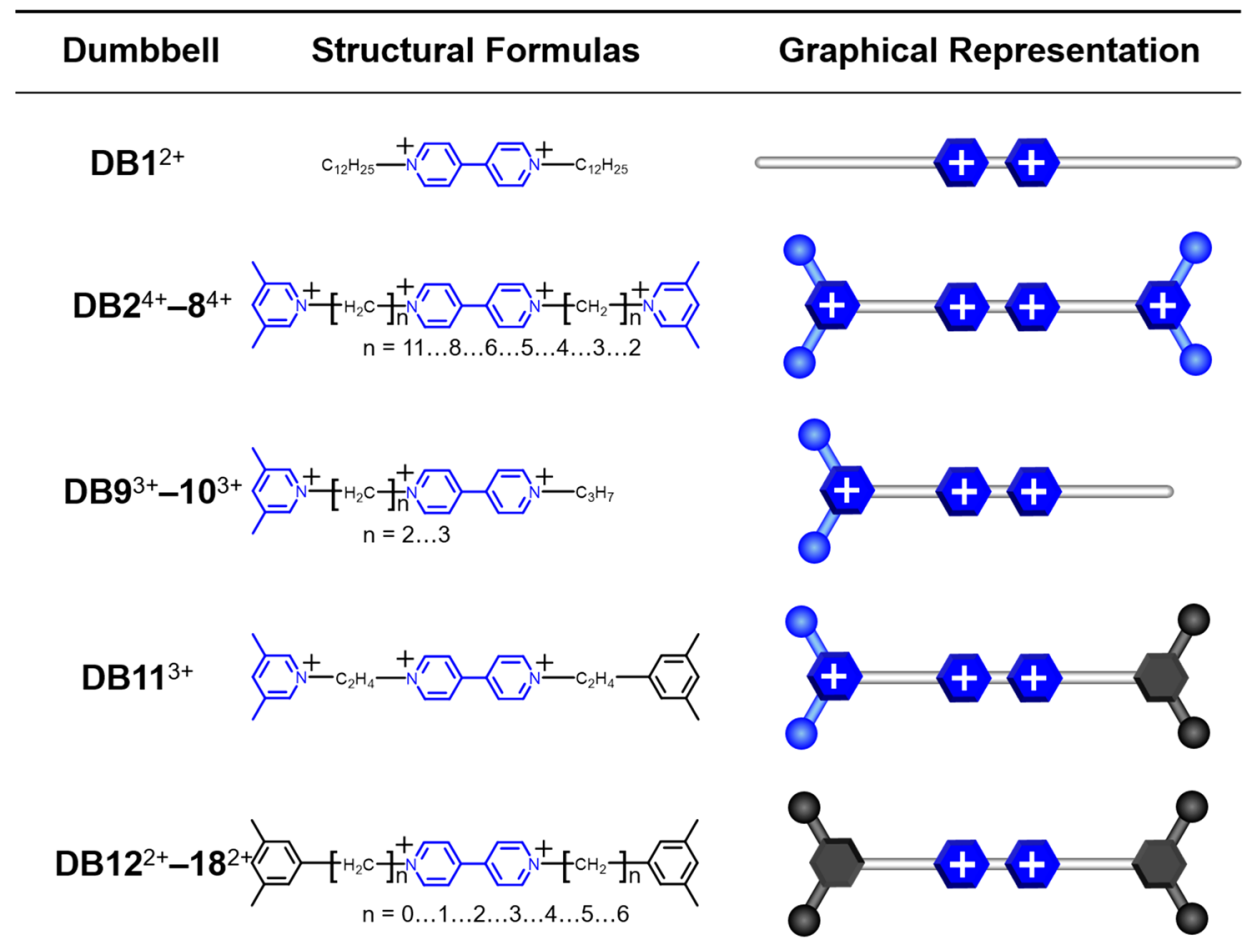

$\mathrm{CBPQT}^{4+} / \mathrm{CBPQT}^{2(\bullet+)}$ rings. Positively charged 3,5-dimethylpyridinium $\left(\mathrm{PY}^{+}\right)$units were then attached to both ends of oligomethylene chains emanating from the central BIPY ${ }^{2+}$ unit. The lengths of the linkers between the $\mathrm{PY}^{+}$termini and the central $\mathrm{BIPY}^{2+}$ units cover the range from 11 to 8 to 6 to 5 to 4 to 3 to $2\left(\mathrm{DB}^{4+}-\mathrm{DB}^{4+}\right)$ methylene groups. In order to probe the influence of the positive charge on the terminal $\mathrm{PY}^{+}$units, $\mathrm{DB}^{3+}$ and $\mathrm{DB} 10^{3+}$ with 2 and 3 methylene groups separating one $\mathrm{PY}^{+}$terminus from the central $\mathrm{BIPY}^{2+}$ unit, while the other substituent is a neutral propyl group, were synthesized. The dumbbell $\mathrm{DB}_{1} 1^{3+}$ can be viewed as being derived from $\mathrm{DB} 9^{3+}$ by replacement of the terminal methyl group on the neutral end by a 3,5-dimethylphenyl (PH) unit, i.e., the neutral analogue of a $\mathrm{PY}^{+}$unit. This $\mathrm{PH}$ unit terminates both ends of $\mathrm{DB} 12^{2+}-\mathrm{DB} 18^{2+}$ with $0,1,2,3,4,5$, and 6 methylene groups between the $\mathrm{PH}$ termini and the central $\mathrm{BIPY}^{2+}$ units. The structural formulas and the corresponding graphical representations of the 18 compounds $\mathrm{DB}^{2+}-\mathrm{DB}^{2} 8^{2+}$ are shown in Table 1.

The syntheses of these 18 compounds were tackled employing three different approaches (Scheme 1) depending on their constitutions. The symmetric dumbbells $\left(\mathrm{DB}^{2+}-\right.$ $\mathrm{DB}^{4+}$ and $\mathrm{DB} 13^{2+}-\mathrm{DB} 18^{2+}$ ) were prepared in one step by performing $S_{\mathrm{N}} 2$ reactions between $4,4^{\prime}$-bipyridine and 2.0 equiv of the corresponding chloride/bromide/tosylate, followed by counterion exchange to give their $\mathrm{PF}_{6}^{-}$salts. The dumbbell $\mathrm{DB} 8^{4+}$ had to be synthesized in two steps on account of the poor solubility of the intermediate bromide salt following the first $S_{N} 2$ reaction and the low reactivity of the second pyridyl unit, deactivated by the electron-withdrawing pyridinium unit. Constitutionally unsymmetrical dumbbells (DB9 ${ }^{3+}-\mathrm{DB}_{1} 1^{3+}$ ) were also prepared in two steps by nucleophilic substitutions, followed by counterion exchange to give their $\mathrm{PF}_{6}{ }^{-}$salts. The dumbbell $\mathrm{DB} 12^{2+}$ was obtained using the Zincke reaction, followed by substitution of the 2,4-dinitrophenyl groups with 3,5-dimethylaniline. All the details describing the synthetic procedures can be found in the Supporting Information (SI).

UV-Vis-NIR Spectroscopic Investigations. To begin with we recorded the UV-Vis-NIR spectra of the trisradical tricationic complexes formed between the $\mathrm{BIPY}^{\bullet+}$-containing dumbbells and the $\mathrm{CBPQT}^{2(\bullet+)}$ ring under reductive conditions. Activated $\mathrm{Zn}$ dust was added to acetonitrile ( $\mathrm{MeCN}$ ) solutions containing equimolar amounts of $\mathrm{CBPQT} \cdot 4 \mathrm{PF}_{6}$ and each of the dumbbells at concentrations of $0.5 \mathrm{mM}$. After the mixture was stirred in an Ar glovebox for 5 min, the excess of $\mathrm{Zn}$ dust was filtered off; the purple filtrates were sealed in a $1 \mathrm{~mm}$ quartz cuvette, and the UV-Vis-NIR spectra were recorded. Although all the dumbbells together with $\mathrm{CBPQT}^{2(\bullet+)}$ display characteristic ${ }^{22,23}$ trisradical tricationic bands around $1100 \mathrm{~nm}$, the intensities of their absorption bands differ.

First, let us compare the UV-Vis-NIR spectra of the equimolar mixture of $\mathrm{DB}^{\bullet+}$ and $\mathrm{CBPQT}^{2(\bullet+)}$ with those of mixtures derived from dumbbells containing two $\mathrm{PY}^{+}$units (Figure 2a). As expected, the equimolar mixture containing $\mathrm{DB}^{\bullet+}$ exhibits a strong NIR absorption band around $1100 \mathrm{~nm}$, while the trisradical tricationic bands for equimolar mixtures of dumbbells $\mathrm{DB}^{2+(\bullet+)}, \mathrm{DB}^{2+(\bullet+)}, \mathrm{DB}^{2+(\bullet+)}$, and $\mathrm{DB} 8^{2+(\bullet+)}$ decrease in their intensities as the oligomethylene linkers between the $\mathrm{PY}^{+}$and $\mathrm{BIPY}^{\bullet+}$ units become shorter. This observation can be explained by the fact that the positively charged $\mathrm{PY}^{+}$units destabilize more significantly the trisradical tricationic complex the closer they are to it. The corresponding increase in the absorption band of the $\mathrm{BIPY}^{\bullet+}$ radical cation at ca. $600 \mathrm{~nm}$ confirms the presence of an increasing proportion of free $\mathrm{BIPY}^{\bullet+}$ radical cations in solution. The influence of the positively charged $\mathrm{PY}^{+}$units also becomes evident by comparing spectra (Figure 2b) of equimolar mixtures of $\mathrm{CBPQT}^{2(\bullet+)}$ with $\mathrm{DB}^{\left(0^{++}\right)}$and $\mathrm{DB}^{+(\bullet+)}$ and those of $\mathrm{CBPQT}^{2(\bullet+)}$ with $\mathrm{DB}^{2+(\bullet+)}$ and $\mathrm{DB}^{2+(\bullet+)}$ : in these cases, the band intensities of the trisradical trications at ca. $1100 \mathrm{~nm}$ are 
Scheme 1. Syntheses of the Dumbbells $\mathrm{DB} 1^{2+}-\mathrm{DB} 18^{2+}$, Isolated as Their $\mathrm{PF}_{6}{ }^{-}$Salts, Following (a) Dialkylation, (b) Sequential Monoalkylation, and (c) the Zincke Reaction

a)

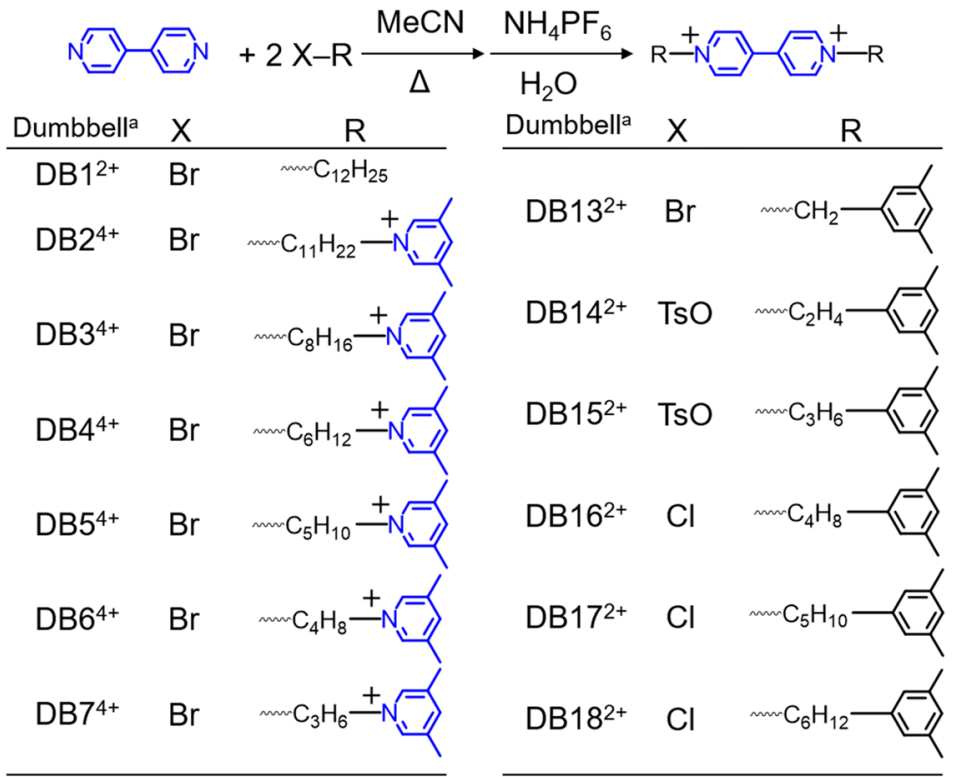

a In all cases the counterions are $\mathrm{PF}_{6}-$

b)

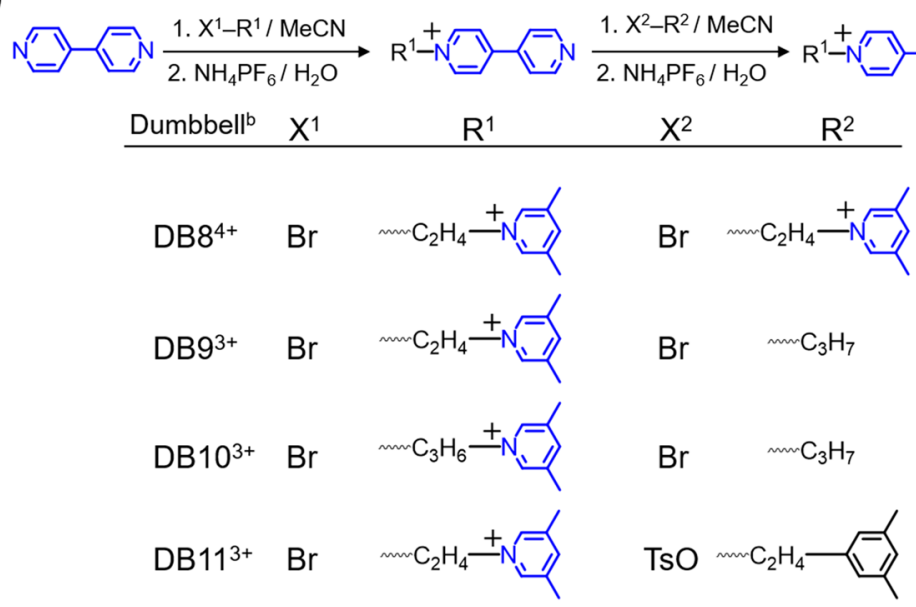

${ }^{\mathrm{b}}$ In all cases the counterions are $\mathrm{PF}_{6}{ }^{-}$

c)

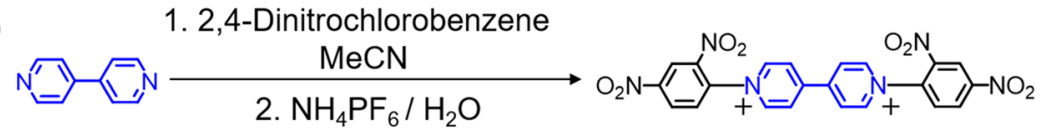

1. 3,5-Dimethylaniline

$\underset{\mathrm{MeCN}}{2 . \mathrm{NH}_{4} \mathrm{PF}_{6} / \mathrm{H}_{2} \mathrm{O}} \longrightarrow$

much stronger for the former than those of the latter. The Coulombic effect is also evident when making comparisons between equimolar mixtures involving $\mathrm{CBPQT}^{2(\bullet+)}$ with $\mathrm{DB}^{+(\bullet+)}$ and $\mathrm{DB}^{\left(0^{+(\bullet+)}\right.}$ and also with $\mathrm{DB}^{2+(\bullet+)}$ and DB8 ${ }^{2+(\bullet+)}$ : irrespective of whether the dumbbells are monoor bis-PY functionalized, the shorter linkers between the $\mathrm{PY}^{+}$ and $\mathrm{BIPY}^{\bullet+}$ units result in weaker trisradical tricationic absorptions. The differences between equimolar mixtures of $\mathrm{CBPQT}^{2(\bullet+)}$ and those dumbbells $\left(\mathrm{DB} 14^{\bullet+}, \mathrm{DB}_{1} 1^{+(\bullet)}\right.$, $\mathrm{DB} 9^{+(\bullet+)}$ and $\left.\mathrm{DB} 8^{2+(\bullet+)}\right)$ containing neutral $\mathrm{PH}$ units and positively charged $\mathrm{PY}^{+}$units are compared in Figure $2 \mathrm{c}$. As in the case of the equimolar mixture of $\mathrm{CBPQT}^{2(\bullet+)}$ with neutral didodecyl-functionalized $\mathrm{DB} 1^{\bullet+}$, the equimolar mixture of $\mathrm{CBPQT}^{2(\bullet+)}$ and $\mathrm{DB} 14^{\bullet+}$ with two neutral PH termini exhibits a much stronger trisradical tricationic NIR band compared with that of an equimolar mixture of $\mathrm{CBPQT}^{2(\bullet+)}$ with its positively charged $\mathrm{DB}^{2+(\bullet+)}$ analogue carrying two $\mathrm{PY}^{+}$termini. The intensity of the trisradical tricationic band of the equimolar mixture of $\mathrm{CBPQT}^{2(\bullet+)}$ with $\mathrm{PY}^{+} / \mathrm{PH}$-terminated $\left.\mathrm{DB}^{+(} 1^{++}\right)$ resides between those of the equimolar mixture of $\mathrm{CBPQT}^{2(\bullet+)}$ with $\mathrm{DB} 14^{\bullet+}$ and $\mathrm{DB} 8^{2+(\bullet+)}$. Moreover, we also noticed that the equimolar mixture of $\mathrm{CBPQT}^{2(\bullet+)}$ and $\mathrm{DB} 1^{+(\bullet+)}$ has a stronger trisradical tricationic absorption band than the equimolar mixture of $\mathrm{CBPQT}^{2(\bullet+)}$ with $\mathrm{DB}^{+(\bullet+)}$, although both 

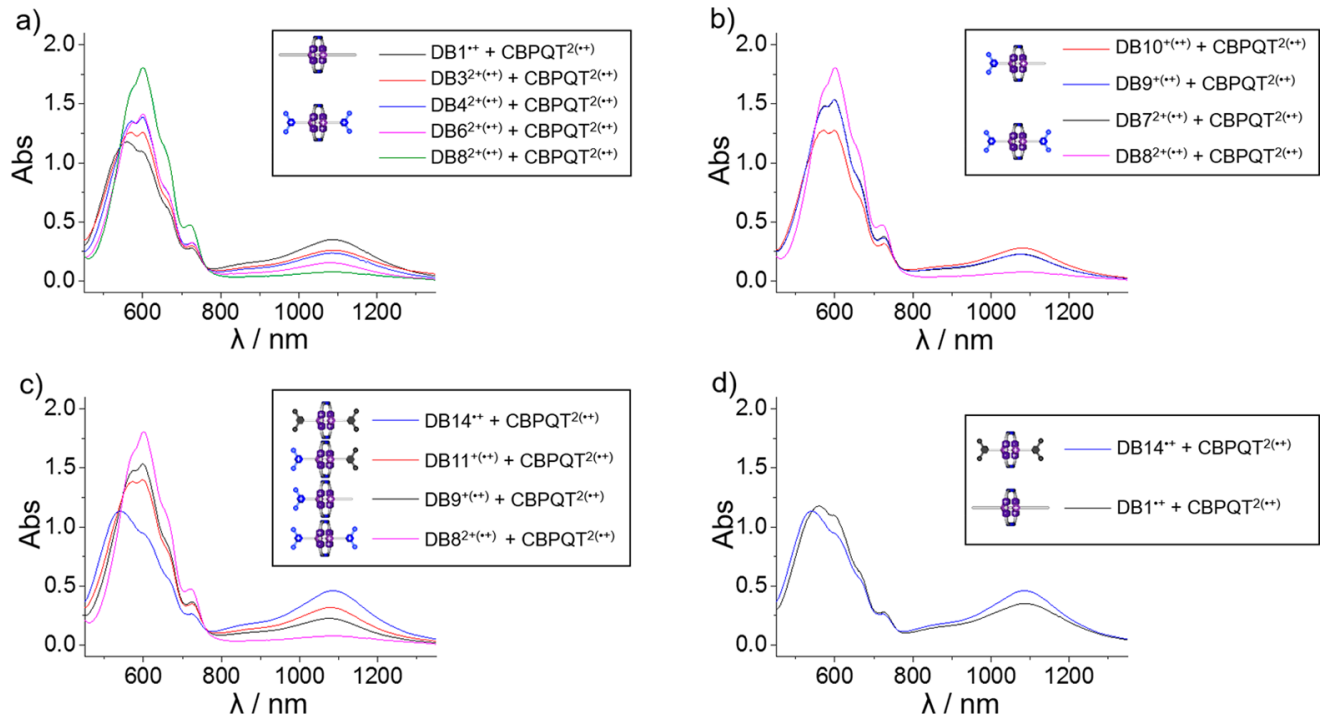

Figure 2. UV-Vis-NIR spectra of equimolar mixtures of $\mathrm{CBPQT}^{2(\bullet+)}$ and different $\mathrm{BIPY}^{\bullet+}$-containing dumbbells recorded in $\mathrm{MeCN}$ at $298 \mathrm{~K}$. Formation of the trisradical tricationic inclusion complex $\mathrm{BIPY}^{\bullet+} \mathrm{CCBPQT}^{2(\bullet+)}$ gives rise to a broad band centered on $1100 \mathrm{~nm}$. The intensity of this band decreases in conjunction with an increase in intensity of the band around $600 \mathrm{~nm}$ comparing (a) dumbbells DB3 $3^{2+(\bullet+)}, \mathrm{DB}^{2+(\bullet+)}, \mathrm{DB}^{2+(\bullet+)}$, and $\mathrm{DB} 8^{2+(\bullet)}$ terminated with $\mathrm{PY}^{+}$units with $\mathrm{DB} 1^{\bullet+}$ lacking $\mathrm{PY}^{+}$terminal unit; (b) dumbbells DB7 $7^{2+(\bullet)}$ and DB8 $8^{2+(\bullet+)}$ terminated with $\mathrm{PY} Y^{+}$units at both ends with $\mathrm{DB}^{+(\bullet+)}$ and $\mathrm{DB} 10^{+(\bullet+)}$ terminated with $\mathrm{PY}^{+}$unit at only one end; (c) dumbbell $\mathrm{DB} 8^{2+(\bullet+)}$ terminated with $\mathrm{PY}^{+}$unit at both ends, $\mathrm{DB}^{+(\bullet+)}$ terminated with a $\mathrm{PY}^{+}$unit at one end, $\mathrm{DB}_{1} 1^{+(\bullet)}$ terminated by a $\mathrm{PY}^{+}$unit at one end and a $\mathrm{PH}$ unit at the other end, and $\mathrm{DB} 14^{\bullet+}$ terminated with $\mathrm{PH}$ units at both ends; and (d) dumbbell $\mathrm{DB} 1^{\bullet+}$ and $\mathrm{DB} 14^{\bullet+}$ terminated with two $\mathrm{PH}$ units at both ends.

$\mathrm{DB} 11^{+(\bullet+)}$ and $\mathrm{DB} 9^{+(\bullet+)}$ contain the same positively charged $\mathrm{PY}^{+}$terminus. In spite of the fact that neither $\mathrm{DB}^{\bullet+}$ nor $\mathrm{DB} 14^{\bullet+}$ contains any positively charged $\mathrm{PY}^{+}$termini, the equimolar mixture of $\mathrm{CBPQT}^{2(\bullet+)}$ with $\mathrm{DB}^{\bullet} 4^{\bullet+}$ exhibits a stronger trisradical tricationic absorption band compared with the case of the equimolar mixture of $\mathrm{CBPQT}^{2(\bullet+)}$ with $\mathrm{DB} 1^{\bullet+}$ (Figure 2d). These observations might suggest that the neutral $\mathrm{PH}$ unit can provide some extra interactions to stabilize the trisradical tricationic complexes.

Binding Constant Measurements. The strengths of binding between the $\mathrm{CBPQT}^{2(\bullet+)}$ ring and the 18 dumbbells containing $\mathrm{BIPY}^{\bullet+}$ units were measured by carrying out titration experiments in an Ar-filled glovebox. The absorptions at ca. $1100 \mathrm{~nm}$ were monitored after transferring of samples in the glovebox to cuvettes which were sealed to the air during the collection of UV-Vis-NIR spectra. For the experimental details and results from these measurements, see the SI, in particular Table S1 and Figures S1-S20. The results, which are summarized in Figure 3, reveal that the association constants $\left(K_{\mathrm{a}}\right)$ for the formation of the trisradical tricationic complexes between the $\mathrm{CBPQT}^{2(\bullet+)}$ ring and the 18 dumbbells containing $\mathrm{BIPY}^{\bullet+}$ units in $\mathrm{MeCN}$ vary (Table 2) over a wide range from $10^{2}$ to $10^{5} \mathrm{M}^{-1}$, with the weakest being $\mathrm{DB} 8^{2+(\bullet+)}$, with $K_{\mathrm{a}}=$ $800 \mathrm{M}^{-1}$, and the strongest being DB14 ${ }^{\bullet+}$, with $K_{\mathrm{a}}=180000$ $\mathrm{M}^{-1}$. In general, the association constants for the complexes involving dumbbells with positively charged $\mathrm{PY}^{+}$termini (the pink, blue, and black lines/points in Figure 3) are significantly smaller than those for dumbbells with neutral $\mathrm{PH}$ termini (the red and green lines/points in Figure 3). The $K_{\mathrm{a}}$ values for the dumbbells terminated by $\mathrm{PY}^{+}$groups are influenced by the number of positive charge(s) (one or two) and the number of methylene groups separating the $\mathrm{PY}^{+}$termini from the centrally located BIPY ${ }^{\bullet+}$ units, i.e., the distance between positive charges in the complexes. For the series of $\mathrm{PY}^{+}$-terminated dumbbells, a decrease is observed (black line in Figure 3) in the $K_{\mathrm{a}}$ values for the complexes as the oligomethylene chains become shorter $(n$

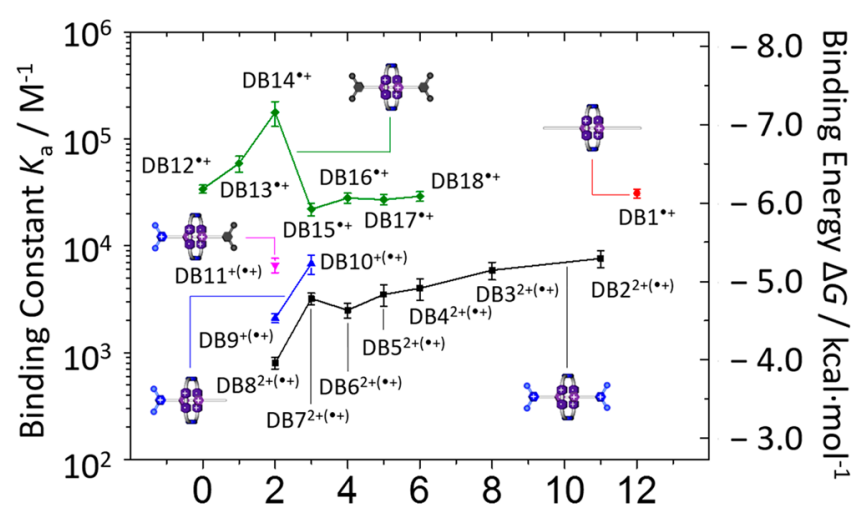

Number of Carbon Atoms in Oligomethylene Links

Figure 3. Comparison of the binding constants of the 18 dumbbells with $\mathrm{CBPQT}^{2(\bullet+)}$ under reducing conditions. The $x$ axis indicates the number of methylene groups in the spacers between the functional groups and the BIPY ${ }^{\bullet+}$ radical cations. The left $y$ axis presents the binding constant on a logarithmic axis, while the right $y$ axis shows the corresponding binding energies. The black line represents the series of dumbbells with bis-PY ${ }^{+}$functionalization; it shows an approximate decrease in binding constants as the spacers become shorter. The same trend is evident in the case of the mono-PY' functionalized DB9 ${ }^{+(\bullet+)}$ and $\mathrm{DB}_{10} 0^{+\bullet+}$, as indicated by the blue line. The green line, which represents the bis- $\mathrm{PH}$-functionalized series, shows a dramatic increase from $\mathrm{DB} 12^{\bullet+}$ to $\mathrm{DB} 14^{\bullet+}$, followed by a dramatic decrease from $\mathrm{DB} 14^{\bullet+}$ to $\mathrm{DB} 15^{\bullet+}$, before remaining constant from $\mathrm{DB} 15^{\bullet+}$ through $\mathrm{DB} 18^{\bullet+}$. DB1 $1^{\bullet+}$ has a binding constant similar to those of $\mathrm{DB} 15^{\circ+}$ $\mathrm{DB} 18^{\bullet+}$, while $\mathrm{DB} 11^{\bullet+}$, bearing mixed $\mathrm{PH}$ and $\mathrm{PY}^{+}$units, presents a binding constant between those of bis-PH-functionalized dumbbells and mono-PY ${ }^{+}$-functionalized DB9 $9^{+(\bullet+)}$.

$=11$ down to 2 in Table 1$)$ on going from $\mathrm{DB}^{2+(\bullet+)}\left(K_{\mathrm{a}}=\right.$ $\left.7600 \mathrm{M}^{-1}\right)$ to $\mathrm{DB}^{2+(\bullet+)}\left(K_{\mathrm{a}}=800 \mathrm{M}^{-1}\right)$. The two halfdumbbells with only one $\mathrm{PY}^{+}$terminus exhibit (blue line in Figure 3) higher $K_{\mathrm{a}}$ values than the series of dual-terminated $\mathrm{PY}^{+}$dumbbells. DB10 $0^{+(\bullet)}$, where $n=3$ in Table 1 , has a higher 
Table 2. Summary of Binding Constants and Binding Energies

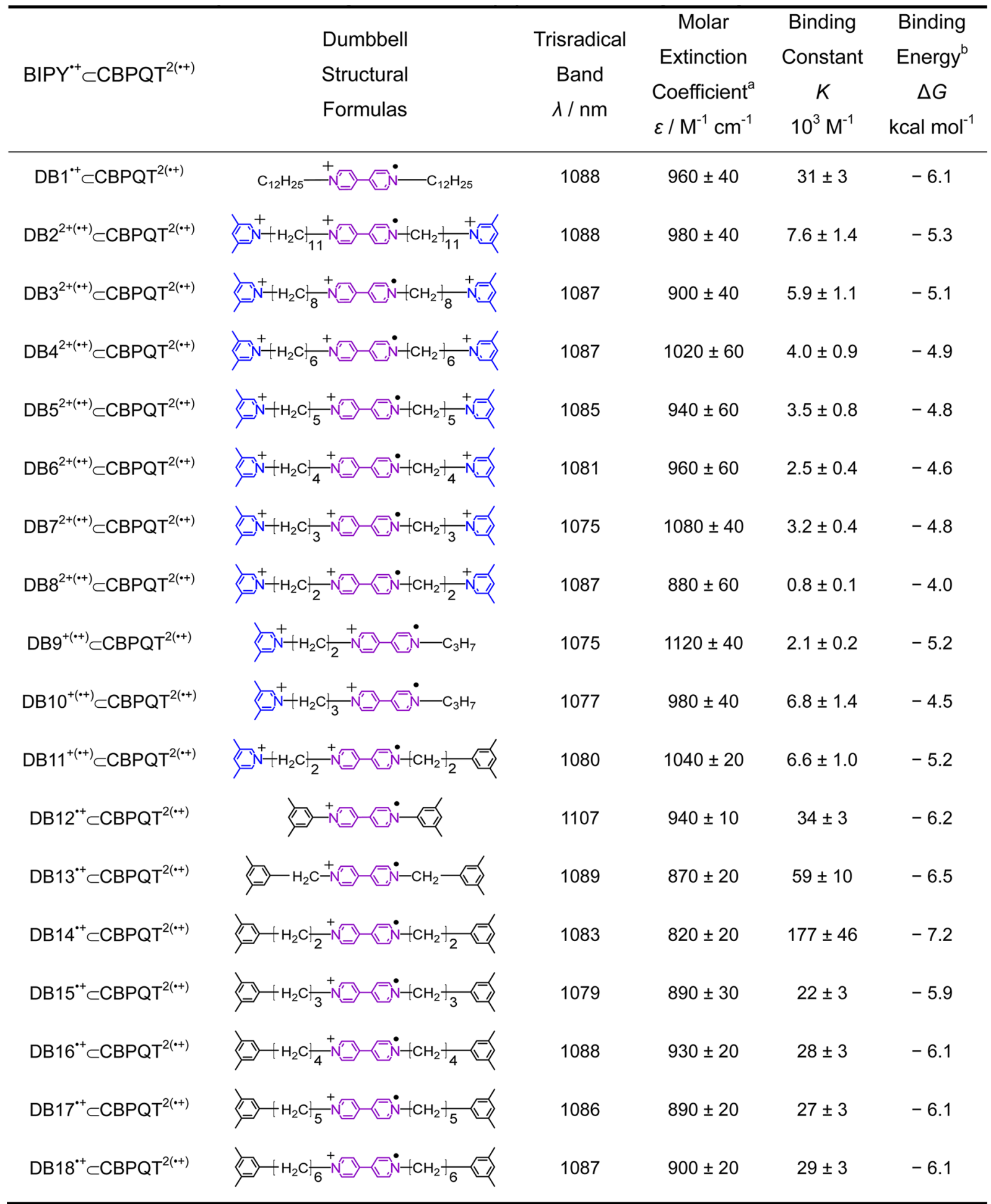

${ }^{a}$ Molar extinction coefficients have been calculated using UV-Vis-NIR titration spectra, assuming all $\mathrm{CBPQT}^{2(\bullet+)}$ forms a trisradical complex when large excess of BIPY ${ }^{\bullet+}$ is present. ${ }^{b}$ Binding energies have been calculated using the equation $\Delta G=-R T \ln K$.

$K_{\mathrm{a}}$ value than $\mathrm{DB}^{+(\bullet+)}$, where $n=2$ in Table 1 . The neutral $\mathrm{PH}$-terminated dumbbells (green line in Figure 3 ) reveal higher $K_{\mathrm{a}}$ values and a more complicated behavior. Dumbbells $\mathrm{DB} 15^{\bullet+}-\mathrm{DB} 18^{\bullet+}$, containing oligomethylene chains with three methylene units $(n=3$ in Table 1$)$ or more $(n=4,5$, 6 in Table 1), show very similar binding strengths to each other and also to $\mathrm{DB} 1^{\bullet+}$ carrying only dodecyl chains: in these cases, there is no Coulombic repulsion to destabilize the trisradical tricationic complexes. Dumbbells DB12 $2^{\bullet+}-\mathrm{DB} 14^{\bullet+}$, where $n=$ 0,1 , and 2, respectively, in Table 1 , however, exhibit a dramatic increase in $K_{\mathrm{a}}$ values, from $34000 \mathrm{M}^{-1}$ for $\mathrm{DB} 12^{\bullet+}$ to 180000 $\mathrm{M}^{-1}$ for $\mathrm{DB} 14^{\bullet+}$, reflecting the fact that additional $\mathrm{C}-\mathrm{H} \cdots \pi$ interactions are coming into play as sources (vide infra) of extra stabilization of their complexes. This interpretation is 
strengthened further on comparing the $K_{\mathrm{a}}$ value of $2100 \mathrm{M}^{-1}$ for the half-dumbbell DB9 $9^{+(\bullet)}$ with that of $6600 \mathrm{M}^{-1}$ for the full dumbbell $\mathrm{DB} 11^{+(\bullet)}$ terminated by a $\mathrm{PH}$ unit which can enter into $\mathrm{C}-\mathrm{H} \cdots \pi$ interactions with the $\mathrm{CBPQT}^{2(\bullet+)}$ ring.

Single-Crystal X-ray Diffraction (XRD). In an attempt to gain a better understanding of the behavior observed in binding strengths between the $\mathrm{CBPQT}^{2(\bullet)}$ rings and the different dumbbells containing BIPY ${ }^{\bullet+}$ units, we decided that solid-state superstructures might yield some valuable co-conformational information. ${ }^{35}$ Single crystals were grown in an Ar-filled glovebox by slowly diffusing $i \operatorname{Pr}_{2} \mathrm{O}$ into $\mathrm{MeCN}$ solutions $(0.5$ $\mathrm{mM}$ ) of the trisradical tricationic complexes derived from the $\mathrm{CBPQT}^{2(\bullet+)}$ ring and dumbbells $\mathrm{DB}^{2+(\bullet+)}, \mathrm{DB}^{2+(\bullet+)}$, $\mathrm{DB}^{+(\bullet+)}, \mathrm{DB}^{\left.+0^{+}+{ }^{+}\right)}, \mathrm{DB} 12^{\bullet+}, \mathrm{DB} 13^{\bullet+}$, and $\mathrm{DB} 14^{\bullet+}$. The Xray crystal data associated with these solid-state superstructures are summarized in the Experimental Section and illustrated in Figures 4 and 5, as well as in the SI in Figures S21-S27. They all reveal 1:1 inclusion complexes in which the BIPY ${ }^{\bullet+}$ units in the dumbbells are encircled ${ }^{23}$ by $\mathrm{CBPQT}^{2(\bullet+)}$ rings. In the case of both the full dumbbells terminated by two $\mathrm{PY}^{+}$units and half dumbbells with only one $\mathrm{PY}^{+}$terminus, the $\mathrm{PY}^{+}$units are directed (Figure 4) away from the charged centers of complexation in order to minimize Coulombic repulsion. It is worth noting that both $\mathrm{DB}^{2+(\bullet+)}$ and $\mathrm{DB} 10^{+(\bullet+)}$, with trismethylene linkers, form stronger complexes in solution than do $\mathrm{DB}^{2+(\bullet+)}$ and DB9 ${ }^{+(\bullet+)}$, with bismethylene linkers. The solid-state superstructures (Figure 5) of the trisradical tricationic complexes formed between the $\mathrm{CBPQT}^{2(\bullet+)}$ ring and a)

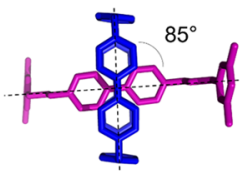

d)

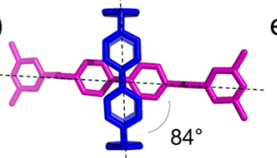

g)
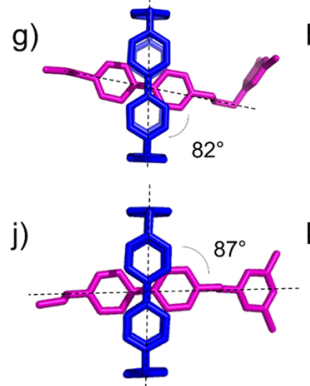

)
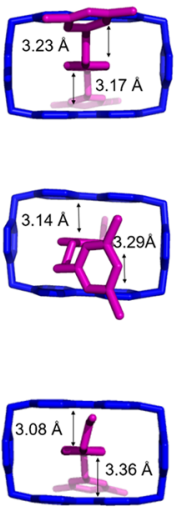

h)

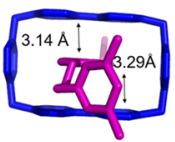

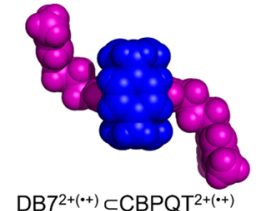

i)
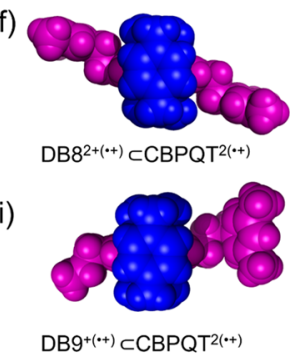

l)

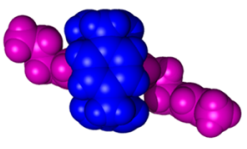

$\mathrm{DB} 10^{+(++)} \subset \mathrm{CBPQT} 2(++)$
Figure 4. Solid-state superstructures of the radical cationic complexes formed between $\mathrm{CBPQT}^{2(\bullet+)}$ and $(\mathrm{a}-\mathrm{c}) \mathrm{DB}^{2+(\bullet+)},(\mathrm{d}-\mathrm{f}) \mathrm{DB}^{2+(\bullet+)}$, $(\mathrm{g}-\mathrm{i}) \mathrm{DB}^{+(\bullet+)}$, and $(\mathrm{j}-\mathrm{l}) \mathrm{DB}^{+0^{+(\bullet)}} .(\mathrm{a}),(\mathrm{d}),(\mathrm{g})$, and $(\mathrm{j})$ are tubular representations of the side-on views, illustrating the angle between the $\mathrm{CBPQT}^{2(\bullet+)}$ ring plane and the BIPY ${ }^{\bullet+}$ unit. (b), (e), (h), and (k) are tubular representations of the plan views, illustrating the distances between the three BIPY ${ }^{\bullet+}$ units in the superstructures. (c), (f), (i), and (l) are space-filling representations of the 1:1 complexes. Solvent molecules and counterions are omitted for the sake of clarity. The solid-state superstructures reveal that the positively charged $\mathrm{PY}^{+}$units are positioned away from the center of the trisradical tricationic complexes in order to minimize Coulombic repulsions.

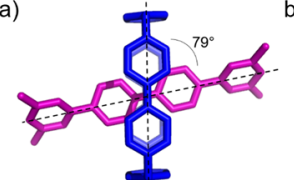

d)

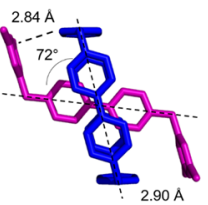

g)

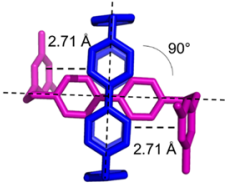

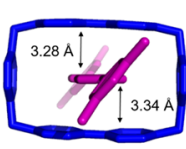

e)

h)

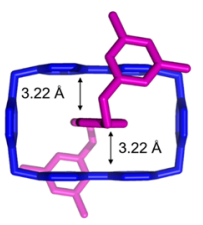

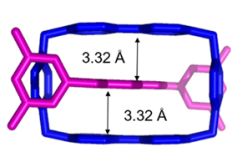

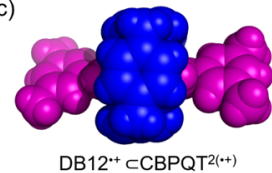

f)

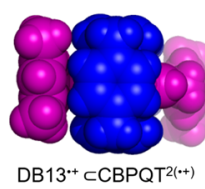

i)

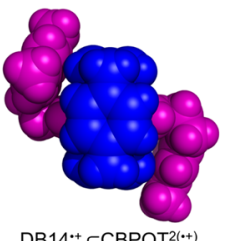

Figure 5. Solid-state superstructures of the radical cationic complexes formed between $\mathrm{CBPQT}^{2(\bullet+)}$ and $(\mathrm{a}-\mathrm{c}) \mathrm{DB}^{\bullet} 2^{\bullet+},(\mathrm{d}-\mathrm{f}) \mathrm{DB}^{\circ} 3^{\bullet+}$, and $(\mathrm{g}-\mathrm{i}) \mathrm{DB} 14^{\bullet+}$. (a), (d), and $(\mathrm{g})$ are tubular representations of the sideon views, illustrating the angle between the $\mathrm{CBPQT}^{2(\bullet+)}$ ring plane and the $\mathrm{BIPY}^{\bullet+}$ unit and with the close contacts between the protons and $\pi$ planes indicated. (b), (e), and (h) are tubular representations of the plan views, illustrating the distances between the three BIPY ${ }^{\bullet+}$ units in the superstructures. (c), (f), and (i) are space-filling representations of the 1:1 complexes. Solvent molecules and counterions are omitted for the sake of clarity. The solid-state superstructures reveal that, on forming trisradical tricationic inclusion complexes with the $\mathrm{CBPQT}^{2(\bullet+)}$ rings, the dumbbells $\mathrm{DB}^{\circ} 3^{\bullet+}$ and $\mathrm{DB} 14^{\bullet+}$ fold back to provide extra interactions that further stabilize the complexes. Although it is not possible for the rigid $\mathrm{DB} 12^{\bullet+}$ dumbbell to acquire additional binding with the $\mathrm{CBPQT}^{2(\bullet+)}$ ring, close contacts are evident in the $\mathrm{DB}_{13^{\bullet++}} \subset \mathrm{CBPQT}^{2(\bullet+)}$ and $\mathrm{DB}^{\circ} 4^{\bullet+} \subset \mathrm{CBPQT}^{2(\bullet+)}$ complexes.

dumbbells $\mathrm{DB} 12^{\bullet+}, \mathrm{DB} 13^{\bullet+}$, and $\mathrm{DB} 14^{\bullet+}$ terminated with neutral $\mathrm{PH}$ groups are very different. In the $\mathrm{DB}^{\circ} 2^{\circ+} \mathrm{C}$ $\mathrm{CBPQT}^{2(\bullet+)}$ complex, the dumbbell is rigid, and the $\mathrm{PH}$ groups are directed away from the $\mathrm{CBPQT}^{2(\bullet+)}$ ring. When there are methylene groups, however, between the BIPY ${ }^{\bullet+}$ unit and the $\mathrm{PH}$ termini as in $\mathrm{DB} 13^{\circ+}$, they fold back to create close contacts between the 3,5-dimethylphenyl rings and the phenylene linkers in the $\mathrm{CBPQT}^{2(\bullet+)}$ rings. The distances from the phenylene protons to the $\mathrm{PH}$ planes are 2.84 and 2.90 $\AA$. When the spacers between the $\mathrm{BIPY}^{\bullet+}$ units and the $\mathrm{PH}$ termini are bismethylenes, as in $\mathrm{DB} 14^{\circ+}$, even more pronounced folding of the $\mathrm{PH}$ termini takes place, as indicated by close contacts of $2.71 \AA$ between the $\beta$-protons on BIPY ${ }^{\bullet+}$ units of the $\mathrm{CBPQT}^{2(\bullet+)}$ rings and the PH planes of the 3,5dimethylphenyl rings. The fact that the $\mathrm{PH}$ termini fold back in the solid-state superstructures of $\mathrm{DB}^{\bullet++} \mathrm{CCBPQT}^{2(\bullet+)}$ and $\mathrm{DB}_{14}{ }^{\bullet+} \mathrm{CCBPQT}^{2(\bullet+)}$ suggests that there are $\mathrm{C}-\mathrm{H} \cdots \pi$ interactions ${ }^{36}$ between the electron-deficient $\mathrm{CBPQT}^{2(\bullet+)}$ rings and the electron-rich 3,5-dimethylphenyl rings. In the former complex the $\mathrm{PH}$ termini form relatively weak $\mathrm{C}-\mathrm{H} \cdots \pi$ interactions with the phenylene linkers in the $\mathrm{CBPQT}^{2(\bullet+)}$ ring, whereas in the latter complex the $\mathrm{C}-\mathrm{H} \cdots \pi$ interactions involving the more electron-deficient $\beta$-protons in the BIPY ${ }^{\bullet+}$ units of the $\mathrm{CBPQT}^{2(\bullet+)}$ rings are stronger, commensurate with the complex having the highest association constant $\left(K_{\mathrm{a}}=\right.$ $180000 \mathrm{M}^{-1}$ ) of all of the 18 dumbbells in $\mathrm{MeCN}$ solution. Although we did not obtain crystals of the $\mathrm{DB}^{\circ} 1^{\bullet+} \mathrm{C}$ $\mathrm{CBPQT}^{2(\bullet+)}$ complex, we can infer that $\mathrm{C}-\mathrm{H} \cdots \pi$ interactions 
Table 3. Comparison of the Binding Free Energies $(\Delta G)$ between Quantum Mechanical Calculations and Experiments

\begin{tabular}{|c|c|c|c|c|c|}
\hline \multirow[b]{2}{*}{ complex $^{a}$} & \multirow[b]{2}{*}{ functional group } & \multicolumn{3}{|c|}{$\mathrm{QM}^{c}$} & \multirow{2}{*}{$\frac{\operatorname{Exp}}{\Delta G(\mathrm{kcal} / \mathrm{mol})}$} \\
\hline & & $\Delta E(\mathrm{kcal} / \mathrm{mol})$ & $\Delta E+\operatorname{BSSE}(\mathrm{kcal} / \mathrm{mol})$ & $\Delta G(\mathrm{kcal} / \mathrm{mol})$ & \\
\hline $\mathrm{DB}^{2+(\bullet+)} \subset \mathrm{CBPQT}^{2(\bullet+)}$ & $2 \mathrm{PY}^{+}$ & -17.05 & -9.82 & -1.39 & -4.0 \\
\hline $\mathrm{DB}^{+(\bullet+)} \mathrm{CCBPQT}^{2(\bullet+)}$ & $1 \mathrm{PY}^{+}$ & -22.58 & -16.09 & -6.38 & -4.5 \\
\hline $\mathrm{DB}^{\bullet+} \subset \mathrm{CBPQT}^{2(\bullet+) b}$ & $0 \mathrm{PY}^{+}(\mathrm{OPH})$ & -27.10 & -21.39 & -8.34 & n.a. \\
\hline $\mathrm{DB}_{11^{+(\bullet+)}} \mathrm{CCBPQT}^{2(\bullet+)}$ & $1 \mathrm{PY}^{+}+1 \mathrm{PH}$ & -26.53 & -19.30 & -9.06 & -5.2 \\
\hline $\mathrm{DB}_{14}{ }^{\bullet+} \mathrm{CCBPQT}^{2(\bullet+)}$ & $2 \mathrm{PH}$ & -35.42 & -28.19 & -13.40 & -7.2 \\
\hline
\end{tabular}

${ }^{a}$ See Table 2 for the structural formulas of DB8, DB9, DB11, and DB14. The chain lengths are all the same $(n=2)$ in these structures. The differences lie in the functional groups in the dumbbell structure: from $2 \mathrm{PY}^{+}$to $2 \mathrm{PH}$, carrying charges from $5^{+}$to $3^{+}$. ${ }^{b} \mathrm{~A}$ structure $\mathrm{DB} 0^{\circ+} \mathrm{C}$ $\mathrm{CBPQT}^{2(\bullet+)}$ without any functional groups $-1,1^{\prime}$-diethyl-4,4'-bipyridinium-was investigated in order to distinguish between the contributions to $\Delta G$ from Coulombic repulsions and $\mathrm{C}-\mathrm{H} \cdots \pi$ interactions. ${ }^{c} \mathrm{QM}$ calculations were performed with the M06 functional at 6-311G(d,p) level with D3 van der Waals correction in the presence of the Poisson-Boltzmann solvation model for MeCN. n.a. = not available
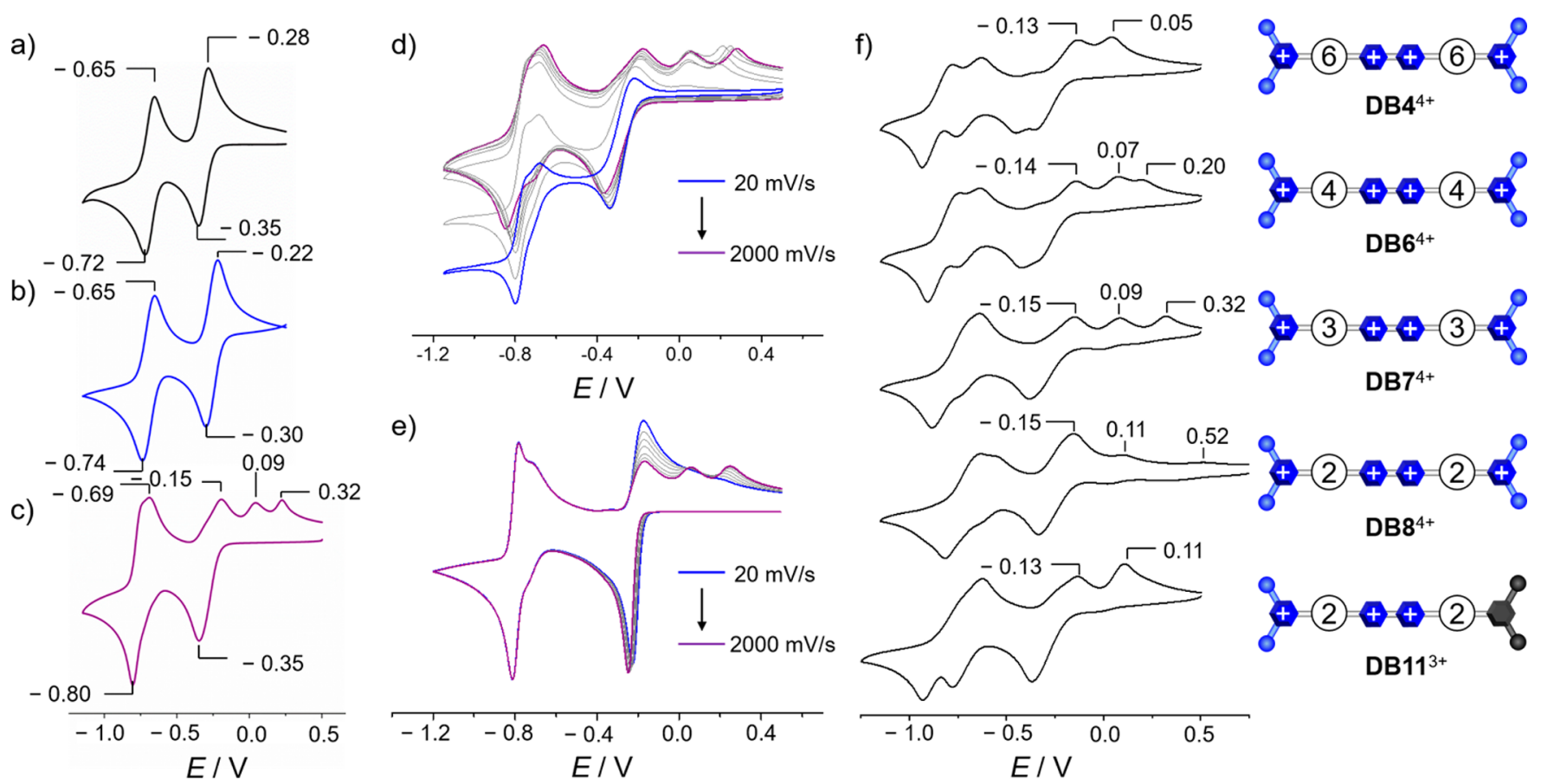

Figure 6. Cyclic voltammograms for (a) $\mathrm{DB} 7 \cdot 4 \mathrm{PF}_{6}$, (b) $\mathrm{CBPQT} \cdot 4 \mathrm{PF}_{6}$, and (c) an equimolar mixture of $\mathrm{DB} 7 \cdot 4 \mathrm{PF}_{6} / \mathrm{CBPQT} \cdot 4 \mathrm{PF}_{6}(0.5 \mathrm{mM}$ in $\left.\mathrm{MeCN}, 0.1 \mathrm{M} \mathrm{TBA} \cdot \mathrm{PF}_{6}, 200 \mathrm{mV} \cdot \mathrm{s}^{-1}, 298 \mathrm{~K}\right)$ indicating that the oxidation peak for the trisradical tricationic complex separates into three oneelectron processes. (d) Normalized experimental $(0.5 \mathrm{mM}$ in $\mathrm{MeCN}, 0.1 \mathrm{M}$ TBA.PF, $298 \mathrm{~K}$ ) and (e) simulated variable scan rate CVs of an equimolar mixture of $\mathrm{DB} 7 \cdot 4 \mathrm{PF}_{6} / \mathrm{CBPQT} \cdot 4 \mathrm{PF}_{6}$ showing that the three oxidation peaks merge into one peak at slow scan rates. The scan rates vary from $20 \mathrm{mV} \cdot \mathrm{s}^{-1}$ (blue curve) through 50,75, 100, 200, 500, 1000, leading up to $2000 \mathrm{mV} \cdot \mathrm{s}^{-1}$ (purple curve). (f) Comparison of CVs of equimolar mixtures of $\mathrm{CBPQT} \cdot 4 \mathrm{PF}_{6}$ with those recorded for $\mathrm{DB} 4 \cdot 4 \mathrm{PF}_{6}, \mathrm{DB} 6 \cdot 4 \mathrm{PF}_{6}, \mathrm{DB} 7 \cdot 4 \mathrm{PF}_{6}, \mathrm{DB} 8 \cdot 4 \mathrm{PF}_{6}$, and $\mathrm{DB} 11 \cdot 3 \mathrm{PF}_{6}$, from top to bottom, at high scan rates $\left(0.5 \mathrm{mM}\right.$ in $\left.\mathrm{MeCN}, 0.1 \mathrm{M} \mathrm{TBA} \cdot \mathrm{PF}_{6}, 2000 \mathrm{mV} \cdot \mathrm{s}^{-1}, 298 \mathrm{~K}\right)$, showing the appearance and shift of the third oxidation peak.

result in it being stronger than $\mathrm{DB} 9^{\bullet+} \mathrm{CCBPQT}^{2(\bullet+)}$ devoid of $\mathrm{C}-\mathrm{H} \cdots \pi$ interactions. In the case of the dumbbells $\mathrm{DB} 15^{\bullet+}$, $\mathrm{DB} 16^{\bullet+}, \mathrm{DB} 17^{\bullet+}$, and $\mathrm{DB} 18^{\bullet+}$, with linkers containing 3, 4, 5, and 6 methylene groups, respectively, presumably the conformations of the linkers exclude the folding back to form $\mathrm{C}-\mathrm{H} \cdots \pi$ interactions so that they exhibit very similar association constants to each other and to $\mathrm{DB}^{\bullet+} \subset \mathrm{CBPQT}^{2(\bullet+)}$.

Quantum Mechanical (QM) Calculations. QM calculations were carried out on these systems using the PoissonBoltzmann solvation model with the M06 density functional and the $6-311 G(\mathrm{~d}, \mathrm{p})$ basis while including the D3 van der Waals corrections that we expect to describe the non-covalent interactions important in these systems. Then, including the vibrational contributions, we evaluated the binding free energies $\left(\Delta G_{\text {binding }}\right)$ between the reduced $\mathrm{CBPQT}^{2(\bullet+)}$ rings and the dumbbells involving reduced BIPY ${ }^{\bullet+}$ units. Here we calculated only trisradical tricationic complexes with bismethylene linkers and various termini $\left(2 \mathrm{PY}^{+}, 1 \mathrm{PY}^{+}, 1 \mathrm{PY}^{+}\right.$plus $1 \mathrm{PH}$, and $\left.2 \mathrm{PH}\right)$ corresponding to $\mathrm{DB}^{2+(\bullet+)}, \mathrm{DB}^{+(\bullet+)}, \mathrm{DB} 1^{+(\bullet+)}$, and $\mathrm{DB} 14^{\bullet+}$, respectively. A model dumbbell $\mathrm{DB}^{\bullet+}-1,1^{\prime}$-diethyl-4, $4^{\prime}$ bipyridinium, an analogue without any termini-was also included in the calculations in order to gain a better understanding of the relationships between the different termini and $\Delta G_{\text {binding. The superstructures associated with }}$ these calculated complexes are shown in Table S3 in the SI. We find that, with the D3 van der Waals corrections and basis set superposition error (BSSE) correction, the QM calculations reproduce (Table 3) qualitatively the experimental results. Thus, we find that the $\Delta G_{\text {binding }}$ data for $\mathrm{DB}^{2+(\bullet+)} \subset$ $\mathrm{CBPQT}^{2(\bullet+)}$ with two $\mathrm{PY}^{+}$termini leads to the lowest calculated binding energy of $-1.39 \mathrm{kcal} / \mathrm{mol}$, which compares reasonably well with the experimental value of $-4.0 \mathrm{kcal} / \mathrm{mol}$. By comparison, $\mathrm{DB}_{1} 4^{\bullet+} \mathrm{CCBPQT}^{2(\bullet+)}$ with two $\mathrm{PH}$ groups has the highest calculated binding free energy of $-13.4 \mathrm{kcal} / \mathrm{mol}$, 
which can be compared with the experimental value of -7.2 $\mathrm{kcal} / \mathrm{mol}$. The calculated $\Delta G_{\text {binding }}$ values for the other complexes are in between those for $\mathrm{DB}^{2+(\bullet+)} \mathrm{CCBPQT}^{2(\bullet+)}$ and $\mathrm{DB} 14^{\bullet+} \mathrm{CCBPQT}^{2(\bullet+)}$ in accordance with the following sequence: $\Delta G_{\text {binding }}^{\mathrm{DB} 8}<\Delta G_{\text {binding }}^{\mathrm{DB} 9}<\Delta G_{\text {binding }}^{\mathrm{DB} 0}<\Delta G_{\text {binding }}^{\mathrm{DB} 11}<$ $\Delta G_{\text {binding, }}^{\mathrm{DB} 14}$ which agrees qualitatively with the experimental data.

Electron Paramagnetic Resonance (EPR) Spectroscopy. The radical-radical interactions in the dumbbell ${ }^{(+)} \subset$ $\mathrm{CBPQT}^{2(\bullet+)}$ complexes were also explored using continuous wave EPR spectroscopy (see Figures S33-35 in the SI). The EPR spectra provide additional verifications of the complexation between $\mathrm{CBPQT}^{2(\bullet+)}$ and the radical cationic dumbbells and indicate an antiferromagnetic coupling between the radicals.

Cyclic Voltammetry (CV). In order to gain a better understanding of the redox processes involved in the assembly and disassembly of radical complexes, CV experiments were performed. The redox processes exhibited by the dumbbells alone (e.g., Figure $6 \mathrm{a}$ for $\mathrm{DB} 7 \cdot 4 \mathrm{PF}_{6}$ ) are very similar to that (Figure 6b) for CBPQT.4PF 6 . The $\mathrm{BIPY}^{2+}$ units experience two sequential one-electron reversible reductions, to their radical cation and neutral states, respectively. Since the redox potential for the $\mathrm{PY}^{+}$units are outside the scan-range $(<-1.20$ $\mathrm{V})$, they are considered to be inert under the experimental conditions. The redox potentials for the dumbbells are shifted to more positive values on account of an increase in inductive effects as the linkers between the $\mathrm{BIPY}^{2+}$ and $\mathrm{PY}^{+}$units become shorter (see SI, Figures S28-S30 and Table S2). When some of the dumbbells are mixed in a 1:1 molar ratio with CBPQT. $4 \mathrm{PF}_{6}$, the oxidation of the trisradical state back to its fully oxidized form becomes separated into three one-electron processes. For example, the $\mathrm{CV}$ (Figure $6 \mathrm{c}$ ) of a 1:1 mixture of DB7.4PF 6 and CBPQT.4PF 6 in $\mathrm{MeCN}$ at a scan rate of 200 $\mathrm{mV} / \mathrm{s}$ illustrates the separation into three peaks. When variable scan-rate CV experiments (Figure 6d and SI, Figure S31) were performed, the three peaks are observed to merge to give one single broad peak at low scan rate $(20 \mathrm{mV} / \mathrm{s})$. A mechanism explaining the $\mathrm{CV}$ data is proposed in Figure 7. The trisradical complex, first of all, loses one electron to form a bisradical complex, resulting in much weaker binding interactions. Under slow scan-rate conditions, we propose that the bisradical complex disassembles in solution on a time scale that is fast compared with the sweep in voltage, resulting in both $\mathrm{CBPQT}^{2+(\cdot)}$ and $\mathrm{BIPY}^{\bullet+}$ being oxidized as separate compounds, giving rise to one overlapping broad peak. Under fast scan-rate conditions, however, the scan rate is faster than the disassembly of the bisradical complex, which has a less favorable oxidation potential compared with that of the trisradical complex on account of the increase in the positive charge which renders this second oxidation potential more positive than the first one. Once the complex has been oxidized back to the monoradical state, the kinetic barrier for the $\mathrm{CBPQT}^{4+}$ ring to dethread increases significantly on account of Coulombic repulsions between $\mathrm{PY}^{+}$and the four positive charges on the $\mathrm{CBPQT}^{4+}$ ring. Consequently, the final oxidation takes place before the dethreading process. The cumulated positive charges cause the final oxidation process to take place at an even more positive potential, resulting in the observation of a third oxidation peak. The proposed mechanism has been tested by digital simulation ${ }^{23,30 c, 37}$ which reveals a behavior (Figure 6e) similar to that recorded in the voltammograms. The three peaks are not observed in all the dumbbells. For those dumbbells $\left(\mathrm{DB} 2 \cdot 4 \mathrm{PF}_{6}, \mathrm{DB} \cdot 4 \mathrm{PF}_{6}\right.$, and $\left.\mathrm{DB} 4 \cdot 4 \mathrm{PF}_{6}\right)$ containing long linkers

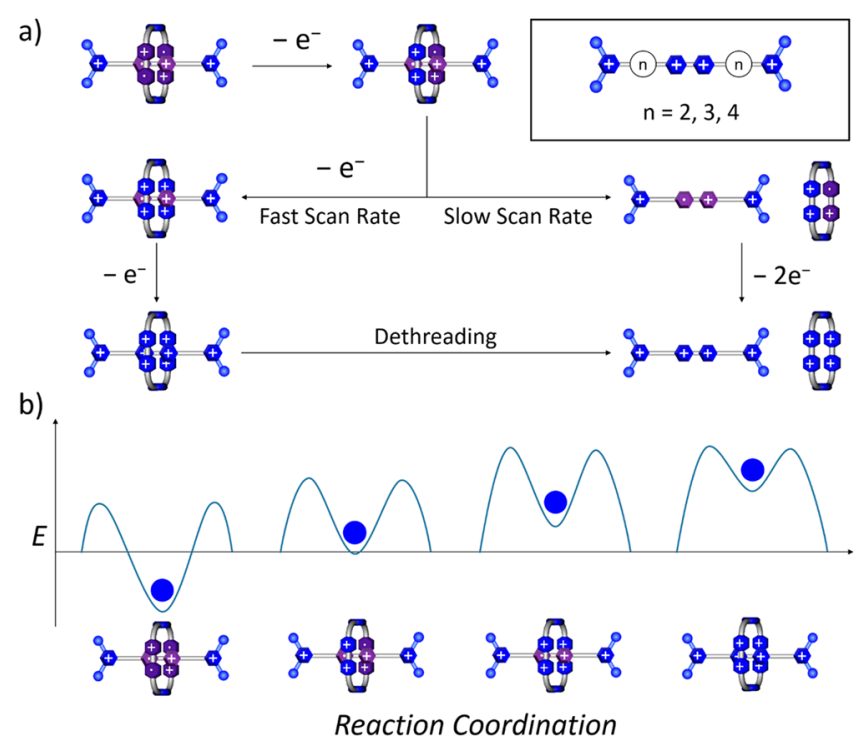

Figure 7. Proposed mechanism for the oxidation of trisradical tricationic complexes to their fully oxidized states. (a) Graphical representations showing the different oxidation pathways under slow and fast CV scan rates, respectively. Oxidation under a fast scan rate results in three one-electron processes at different potentials, while oxidation under a slow scan rate results in three $\mathrm{BIPY}^{\circ+}$ radical cations being oxidized to $\mathrm{BIPY}^{2+}$ dications at more or less the same potentials. (b) Idealized energy profiles for the complexes at different oxidation states. The trisradical tricationic complexes (left) are associated with strong binding interactions, while the bisradical tetracationic complexes (middle left) experience much weaker binding. Although the monoradical species (middle right) are thermodynamically unfavorable, increased Coulombic barriers hinder dethreading of the $\mathrm{CBPQT}^{4+}$ ring, resulting in a metastable species being observed in the high scan rate CV experiments. The fully oxidized species (right) are even higher in energy and so dissociate very quickly.

between the $\mathrm{PY}^{+}$and the $\mathrm{BIPY}^{2+}$ units, there is sufficient space for the $\mathrm{CBPQT}^{4+}$ ring to reside on the linkers instead of being forced to encircle the BIPY ${ }^{\bullet+}$ units, and so the final oxidation occurs at the same potential as the second one, resulting (Figures $6 \mathrm{f}$ and S31) in only two peaks. ${ }^{22,23,30 c}$ Three oxidation peaks are only observed in the cases of $\mathrm{DB} 6 \cdot 4 \mathrm{PF}_{6}, \mathrm{DB} 7 \cdot 4 \mathrm{PF}_{6}$, and $\mathrm{DB} 8.4 \mathrm{PF}_{6}$, in which the third oxidation potential shifts significantly as the number of carbon atoms in the linkers is decreased from four to two since the $\mathrm{CBPQT}^{4+}$ ring is more restricted in $\mathrm{DB}^{2+(\bullet+)}$ than it is in $\mathrm{DB}^{2+(\bullet+)}$. In $\mathrm{DB} 11^{+(\bullet+)}$, with Coulombic repulsion operating only from one end of the dumbbell, a third oxidation peak is not observed (Figure 6f) since the $\mathrm{CBPQT}^{4+}$ ring can make a quick exit from the neutral end of the dumbbell.

\section{CONCLUSION}

An assortment of no less than 18 dumbbells containing within their oligomethylene chains centrally located $4,4^{\prime}$-bipyridinium radical cationic $\left(\mathrm{BIPY}^{\bullet+}\right)$ units, and terminated in some instances by positively charged 3,5-dimethylpyridium $\left(\mathrm{PY}^{+}\right)$ groups and in other cases by neutral 3,5-dimethylphenyl (PH) groups, have been evaluated for their propensities to act as substrates for the cyclobis(paraquat-p-phenylene) bisradical dicationic $\left(\mathrm{CBPQT}^{2(\bullet+)}\right)$ receptor. The $\mathrm{BIPY}^{\bullet+}$ units in these dumbbells serve as radical recognition sites for the $\mathrm{CBPQT}^{2(\bullet+)}$ ring. The dumbbells exhibit a wide range of binding abilities for the ring, depending on whether their termini are charged $\left(\mathrm{PY}^{+}\right)$ 
or neutral $(\mathrm{PH})$. The strengths of the 1:1 complexes formed between the dumbbells and the ring are curtailed severely by the existence of charged termini and enhanced in the presence of neutral termini. Solid-state superstructures of some of the 1:1 radical complexes reveal that the neutral aromatic termini can serve as sources of additional stabilization involving $\mathrm{C}-\mathrm{H} \cdots \pi$ interactions between the ring and dumbbells in folded-back conformations. CV shows quite convincingly that the charged ring dissociates more rapidly from the neutral ends of the dumbbells than from their charged ends. The thermodynamic and kinetic data gleaned from this radical study in physical organic chemistry find relevance in the design and synthesis of machines that operate away from equilibrium. ${ }^{31,32}$ For example, the recently introduced artificial molecular pump ${ }^{32 a}$ with a BIPY-C2-isopropylphenyl portion has an obviously higher pumping efficiency ( $\sim 90 \%$ yield) compared with the initial system $^{31 a}$ without the C2-isopropylphenyl portion ( $70 \%$ yield). We believe the folding-back phenomenon also exists in the case of an artificial molecular pump in its radical state and promotes binding between the $\mathrm{BIPY}^{\bullet+}$ unit in the pump and the $\mathrm{CBPQT}^{2(\bullet+)}$ ring.

\section{EXPERIMENTAL SECTION}

Synthesis. CBPQT.4PF $6{ }^{38} \mathrm{DB} 1 \cdot 2 \mathrm{PF}_{6},{ }^{39}$ and $\mathrm{DB} 7 \cdot 2 \mathrm{PF}_{6}{ }^{31 a}$ were prepared according to literature procedures. The detailed synthetic procedures and full characterizations of new compounds are provided in the SI.

Binding Constant Measurements. An excess of activated $\mathrm{Zn}$ dust was added to a $\mathrm{MeCN}$ solution $\left(\sim 2 \mathrm{~mL}, \sim 5.0 \times 10^{-4} \mathrm{M}\right)$ of $\mathrm{CBPQT} \cdot 4 \mathrm{PF}_{6}$, and the reaction mixture was stirred under $\mathrm{Ar}$ in a glovebox for $5 \mathrm{~min}$. A MeCN solution $\left(\sim 3.0 \times 10^{-2} \mathrm{M}\right)$ of DB1.2PF, $\mathrm{DB} 2-7 \cdot 4 \mathrm{PF}_{6}, \mathrm{DB} 8-10 \cdot 3 \mathrm{PF}_{6}$, or $\mathrm{DB} 11-18 \cdot 2 \mathrm{PF}_{6}$ was titrated into $\mathrm{CBPQT} \cdot 4 \mathrm{PF}_{6}$ solution. After each titration, the mixture was stirred for $1 \mathrm{~min}$, and then $0.35 \mathrm{~mL}$ of the reaction mixture was filtered and sealed in a $1 \mathrm{~mm}$ UV cuvette. Vis-NIR spectra were recorded from 1500 to $450 \mathrm{~nm}$, and the cuvette was then returned to the glovebox. The combined reaction mixture was titrated repeatedly until the trisradical band $(\sim 1080 \mathrm{~nm})$ reached saturation (4-8 equiv of the dumbbells). The detailed data processing can be found in the SI.

Single-Crystal XRD. An excess of activated $\mathrm{Zn}$ dust was added to a mixture of CBPQT. $4 \mathrm{PF}_{6}(0.6 \mathrm{mg}, 0.5 \mu \mathrm{mol})$, and the dumbbells $(0.5$ $\mu$ mol, DB8.4PF $, \mathrm{DB}_{6} \cdot 4 \mathrm{PF}_{6}, \mathrm{DB} 10 \cdot 4 \mathrm{PF}_{6}, \mathrm{DB} 12 \cdot 2 \mathrm{PF}_{6}, \mathrm{DB} 13 \cdot 2 \mathrm{PF}_{6}$, or $\left.\mathrm{DB} 14 \cdot 2 \mathrm{PF}_{6}\right)$ in $\mathrm{MeCN}(1 \mathrm{~mL})$ in a glovebox under an atmosphere of $\mathrm{Ar}$, and the mixtures were stirred for $30 \mathrm{~min}$. After filtering, the purple solutions were subjected to slow vapor diffusion with ${ }^{i} \operatorname{Pr}_{2} \mathrm{O}$ at $0{ }^{\circ} \mathrm{C}$. The solid-state superstructure of DB7CCBPQT. $6 \mathrm{PF}_{6}$ has been published in a previous report. ${ }^{31 a}$ All the other crystal data are summarized briefly below. Detailed data can be found in the SI.

DB8CCBPQT.5PF $. \mathrm{C}_{72} \mathrm{H}_{78} \mathrm{~F}_{30} \mathrm{~N}_{12} \mathrm{P}_{5}, M=1836.34$, triclinic, space group $P \overline{1}$ (no. 2), $a=13.9238(14), b=18.0258(17)$, and $c=$ 19.2008(18) $\AA, \alpha=87.542(5), \beta=74.700(6)$, and $\gamma=83.934(6)^{\circ}, V=$ 4621.8(8) $\AA^{3}, Z=2, T=99.99, \mu(\mathrm{Cu} \mathrm{K} \alpha)=1.858,31230$ reflections measured, 14749 unique $\left(R_{\text {int }}=0.0624\right)$ which were used in all calculations. The final $w R\left(F_{2}\right)$ was 0.5072 (all data).

$D B 9 \subset C B P Q T \cdot 4 P F_{6} . \mathrm{C}_{59} \mathrm{H}_{62} \mathrm{~F}_{24} \mathrm{~N}_{7} \mathrm{P}_{4}, M=1449.03$, triclinic, space group $P \overline{1}$ (no. 2), $a=16.640(4), b=16.710(3)$, and $c=17.160(4) \AA$, $\alpha=75.037(13), \beta=70.814(13)$, and $\gamma=62.956(14)^{\circ}, V=3979.9(16)$ $\AA^{3}, Z=2, T=100.02 \mathrm{~K}, \mu(\mathrm{Cu} \mathrm{K} \alpha)=1.710 \mathrm{~mm}^{-1}, D_{\text {calc }}=1.209 \mathrm{~g} /$ $\mathrm{mm}^{3}, 12511$ reflections measured $(5.498 \leq 2 \theta \leq 108.322)$, 8609 unique $\left(R_{\text {int }}=0.0596, R_{\text {sigma }}=0.1371\right)$ which were used in all calculations. The final $R_{1}$ was $0.1078(I>2 \sigma(I))$, and $w R_{2}$ was 0.3129 (all data).

$D B 10 \subset C B P Q T \cdot 4 P F_{6} \cdot \mathrm{C}_{61} \mathrm{H}_{64.5} \mathrm{~F}_{24} \mathrm{~N}_{85} \mathrm{P}_{4}, M=1496.59$, triclinic, space group $P \overline{1}$ (no. 2), $a=13.8924(9), b=19.3041(11)$, and $c=$ 28.5592(17) $\AA, \alpha=87.962(4), \beta=83.733(4)$, and $\gamma=75.084(4)^{\circ}, V=$ $7356.5(8) \AA^{3}, Z=4, T=100(2) \mathrm{K}, \mu(\mathrm{Cu} \mathrm{K} \alpha)=1.874 \mathrm{~mm}^{-1}, D_{\text {calc }}=$ $1.351 \mathrm{~g} / \mathrm{mm}^{3}, 14372$ reflections measured $(3.112 \leq 2 \theta \leq 101.114)$,
14372 unique $\left(R_{\text {sigma }}=0.1201\right)$ which were used in all calculations. The final $R_{1}$ was $0.1187(I>2 \sigma(I))$, and $w R_{2}$ was 0.3391 (all data).

$D B 12 \subset C B P Q T \cdot 3 P F_{6} . \mathrm{C}_{64} \mathrm{H}_{61} \mathrm{~F}_{18} \mathrm{~N}_{7} \mathrm{P}_{3}, M=1363.10$, monoclinic, space group $C 2 / m$ (no. 12), $a=27.8633(18), b=19.6876(13)$, and $c$ $=14.3635(9) \AA, \beta=121.019(2)^{\circ}, V=6752.5(8) \AA^{3}, Z=4, T=99.99$ $\mathrm{K}, \mu(\mathrm{Cu} \mathrm{K} \alpha)=1.635 \mathrm{~mm}^{-1}, D_{\text {calc }}=1.341 \mathrm{~g} / \mathrm{mm}^{3}, 23953$ reflections measured $(7.182 \leq 2 \theta \leq 130.168), 5897$ unique $\left(R_{\text {int }}=0.0279, R_{\text {sigma }}\right.$ $=0.0237)$ which were used in all calculations. The final $R_{1}$ was 0.1005 $(I>2 \sigma(I))$, and $w R_{2}$ was 0.3082 (all data).

DB13CCBPQT $3.5 P F_{6}$. $\mathrm{C}_{146} \mathrm{H}_{151} \mathrm{~F}_{42} \mathrm{~N}_{21} \mathrm{P}_{7}, \mathrm{M}=3214.66$, monoclinic, space group $P 2_{1} / n$ (no. 14), $a=16.6492(7), b=19.7296(9)$ ), and $c=$ $22.6647(10) \AA, \beta=95.147(3)^{\circ}, V=7414.9(6) \AA^{3}, Z=2, T=99.99 \mathrm{~K}$, $\mu(\mathrm{Cu} \mathrm{K} \alpha)=1.751 \mathrm{~mm}^{-1}, D_{\text {calc }}=1.440 \mathrm{~g} / \mathrm{mm}^{3}, 35068$ reflections measured $(5.95 \leq 2 \theta \leq 130.378), 12522$ unique $\left(R_{\text {int }}=0.0514, R_{\text {sigma }}\right.$ $=0.0529)$ which were used in all calculations. The final $R_{1}$ was 0.0582 $(I>2 \sigma(I))$, and $w R_{2}$ was 0.1747 (all data).

$D B 14 C C B P Q T \cdot 3 P F_{6} \cdot \mathrm{C}_{70} \mathrm{H}_{72} \mathrm{~F}_{18} \mathrm{~N}_{8} \mathrm{P}_{3}, M=1460.26$, triclinic, space group $P \overline{1}$ (no. 2), $a=9.938(2), b=13.616(3)$, and $c=14.482(3) \AA$, $\alpha$ $=113.563(6), \beta=99.933(7)$, and $\gamma=101.953(7)^{\circ}, V=1684.5(6) \AA^{3}$, $Z=1, T=99.99, \mu(\mathrm{Cu} \mathrm{K} \alpha)=1.682,31989$ reflections measured, 6073 unique $\left(R_{\text {int }}=0.0257\right)$ which were used in all calculations. The final $w R\left(F_{2}\right)$ was 0.0824 (all data).

Crystallographic data (excluding structure factors) for all the structures reported in this Article have been deposited with the Cambridge Crystallographic Data Centre as supplementary publication nos. CCDC-1476153, CCDC-1476154, CCDC-1476155, CCDC1476156, CCDC-1476157, and CCDC-1476158.

Density Functional Theory (DFT) Calculations. DFT calculations were performed at the level of $\mathrm{M06}^{40} / 6-311 \mathrm{G}(\mathrm{d}, \mathrm{p})^{41}$ with D3 van der Waals correction ${ }^{42}$ in the presence of the Poisson-Boltzmann solvation $\operatorname{model}^{43}$ for $\mathrm{MeCN}\left(\varepsilon=37.5\right.$ and $\left.R_{0}=2.18 \AA\right)$ as implemented in with Jaguar 8.2. ${ }^{44}$ Unrestricted calculations were applied to molecules and complexes with unpaired electrons. Detailed information on charges and multiplicities used in the calculations is listed in the SI. Counterpoise calculations were used to correct for the problem of $\mathrm{BSSE}^{45}$ to binding energies. Frequencies were derived from semiempirical quantum chemistry method $\mathrm{PM} 7^{46}$ with consideration of solvation implemented in MOPAC 2012. ${ }^{47}$

Gibbs free energies were calculated by the following formula:

$$
G_{298 \mathrm{~K}}=E+G_{\text {solv }}+\mathrm{ZPE}+H_{\mathrm{vib}}+6 k T-T S_{\text {mod }}
$$

where $S_{\text {mod }}=S_{\text {vid }}+0.54\left(S_{\text {trans }}+S_{\text {rot }}\right)+0.24$ is Wertz's approximation ${ }^{48}$ for the entropy fit to the experimental solvation of small molecules.

CV. Each dumbbell compound $(1 \mathrm{mmol})$ was dissolved in a $1 \mathrm{~mL}$ MeCN solution (TBA.PF $6.1 \mathrm{M}$ ). Next, $0.5 \mathrm{~mL}$ of the dumbbell solution was mixed with $0.5 \mathrm{~mL}$ of $\mathrm{MeCN}$ solution $\left(\mathrm{CBPQT} \cdot 4 \mathrm{PF}_{6}, 1\right.$ $\mathrm{mM}$, TBA.PF ${ }_{6} 0.1 \mathrm{M}$ ) in order to prepare the $1: 1$ dumbbell/CBPQT ${ }^{4+}$ samples, while the other $0.5 \mathrm{~mL}$ of the dumbbell solution was diluted with $0.5 \mathrm{~mL}$ of $\mathrm{MeCN}$ solution $\left(\mathrm{TBA} \cdot \mathrm{PF}_{6}, 0.1 \mathrm{M}\right.$ ) in order to prepare the dumbbell-only samples with an analyte concentration of $0.5 \mathrm{mM}$. The simulation is generated using DigiSim 3.03b software purchased from BASi Company.

\section{ASSOCIATED CONTENT}

\section{Supporting Information}

The Supporting Information is available free of charge on the ACS Publications website at DOI: 10.1021/jacs.6b04343.

Synthetic procedures and further details; characterization by UV-Vis-NIR spectroscopy, X-ray crystallography, and EPR spectroscopy; and DFT calculations (PDF)

$\mathrm{X}$-ray data for $\mathrm{DB} 8 \mathrm{CCBPQT} \cdot 5 \mathrm{PF}_{6}(\mathrm{CIF})$

$\mathrm{X}$-ray data for $\mathrm{DB} 9 \subset \mathrm{CBPQT} \cdot 4 \mathrm{PF}_{6}(\mathrm{CIF})$

$\mathrm{X}$-ray data for DB10СCBPQT.4PF 6 (CIF)

$\mathrm{X}$-ray data for DB12СCBPQT.3PF 6 (CIF)

$\mathrm{X}$-ray data for DB13СCBPQT-3.5PF 6 (CIF)

$\mathrm{X}$-ray data for DB14CCBPQT.3PF 6 (CIF) 


\section{AUTHOR INFORMATION}

\section{Corresponding Author}

*stoddart@northwestern.edu

\section{Notes}

The authors declare no competing financial interest.

\section{ACKNOWLEDGMENTS}

This research is supported by National Science Foundation (NSF) under grant no. CHE-1308107. T.C., H.X., and W.A.G. thank the Joint Center for Artificial Photosynthesis, a DOE Energy Innovation Hub, supported through the Office of Science of the U.S. Department of Energy under Award DESC0004993. This work was also supported by the NSF under grant no. CHE-1565925 (M.R.W.). The authors acknowledge the Integrated Molecular Structure Education and Research Center (IMSERC) at Northwestern University for NMR and HRMS characterizations. We thank Dr. Amy Sarjeant and Charlotte C. Stern for solving the single-crystal X-ray structures. C.C. thanks the Chinese Scholarship Council for the Award for Outstanding Self-Financed Students Abroad and Foresight Institute for the Distinguished Student Award. A.C.F. acknowledges support from the Earth-Life Science Institute. J.C.B. acknowledges postdoctoral support from the Howard Hughes Medical Institute through the Life Sciences Research Foundation.

\section{REFERENCES}

(1) (a) de Silva, A. P. Molecular Logic-Based Computation; RSC Publishing: Cambridge, 2012. (b) Lehn, J.-M. Angew. Chem., Int. Ed. Engl. 1990, 29, 1304. (c) Stupp, S. I.; LeBonheur, V.; Walker, K.; Li, L. S.; Huggins, K. E.; Keser, M.; Amstutz, A. Science 1997, 276, 384. (d) Lohmeijer, B. G. G.; Schubert, U. S. Angew. Chem., Int. Ed. 2002, 41, 3825. (e) De Greef, T. F. A.; Smulders, M. M. J.; Wolffs, M.; Schenning, A. P. H. J.; Sijbesma, R. P.; Meijer, E. W. Chem. Rev. 2009, 109, 5687. (f) Bandy, T. J.; Brewer, A.; Burns, J. R.; Marth, G.; Nguyen, T.; Stulz, E. Chem. Soc. Rev. 2011, 40, 138. (g) Aida, T.; Meijer, E. W.; Stupp, S. I. Science 2012, 335, 813. (h) Appel, E. A.; del Barrio, J.; Loh, X. J.; Scherman, O. A. Chem. Soc. Rev. 2012, 41, 6195. (i) Dong, R. J.; Zhou, Y. F.; Huang, X. H.; Zhu, X. Y.; Lu, Y. F.; Shen, J. Adv. Mater. 2015, 27, 498. (j) Werber, J. R.; Osuji, C. O.; Elimelech, M. Nat. Rev. Mater. 2016, 1, 16018. (k) Lutz, J.-F.; Lehn, J.-M.; Meijer, E. W.; Matyjaszewski, K. Nat. Rev. Mater. 2016, 1, 16024.

(2) Lehn, J.-M. Supramolecular Chemistry: Concepts and Perspectives; Wiley-VCH: Weinheim, 2006.

(3) (a) McQuade, D. T.; Pullen, A. E.; Swager, T. M. Chem. Rev. 2000, 100, 2537. (b) Thomas, S. W.; Joly, G. D.; Swager, T. M. Chem. Rev. 2007, 107, 1339. (c) Su, X.; Aprahamian, I. Chem. Soc. Rev. 2014, 43, 1963. (d) Yeung, M. C. L.; Yam, V. W. W. Chem. Soc. Rev. 2015, 44, 4192. (e) Sun, X. L.; James, T. D. Chem. Rev. 2015, 115, 8001.

(4) (a) de las Heras Alarcón, C.; Pennadam, S.; Alexander, C. Chem. Soc. Rev. 2005, 34, 276. (b) Cohen Stuart, M. A.; Huck, W. T. S.; Genzer, J.; Müller, M.; Ober, C.; Stamm, M.; Sukhorukov, G. B.; Szleifer, I.; Tsukruk, V. V.; Urban, M.; Winnik, F.; Zauscher, S.; Luzinov, I.; Minko, S. Nat. Mater. 2010, 9, 101. (c) Wojtecki, R. J.; Meador, M. A.; Rowan, S. J. Nat. Mater. 2011, 10, 14. (d) Yan, X. Z.; Wang, F.; Zheng, B.; Huang, F. H. Chem. Soc. Rev. 2012, 41, 6042. (e) Yang, Y.; Urban, M. W. Chem. Soc. Rev. 2013, 42, 7446. (f) Liu, K.; Kang, Y. T.; Wang, Z. Q.; Zhang, X. Adv. Mater. 2013, 25, 5530. (g) Ma, X.; Tian, H. Acc. Chem. Res. 2014, 47, 1971.

(5) (a) Vallet-Regí, M.; Balas, F.; Arcos, D. Angew. Chem., Int. Ed. 2007, 46, 7548. (b) Li, Z. X.; Barnes, J. C.; Bosoy, A.; Stoddart, J. F.; Zink, J. I. Chem. Soc. Rev. 2012, 41, 2590.

(6) (a) Kang, J. M.; Rebek, J., Jr. Nature 1997, 385, 50. (b) Yoshizawa, M.; Tamura, M.; Fujita, M. Science 2006, 312, 251. (c) Pluth, M. D.; Bergman, R. G.; Raymond, K. N. Science 2007, 316, 85. (d) Liu, J. W.; Chen, L. F.; Cui, H.; Zhang, J. Y.; Zhang, L.; Su, C. Y. Chem. Soc. Rev.
2014, 43, 6011. (e) Raynal, M.; Ballester, P.; Vidal-Ferran, A.; van Leeuwen, P. W. N. M. Chem. Soc. Rev. 2014, 43, 1734. (f) Raynal, M.; Ballester, P.; Vidal-Ferran, A.; van Leeuwen, P. W. N. M. Chem. Soc. Rev. 2014, 43, 1660. (g) Kaphan, D. M.; Levin, M. D.; Bergman, R. G.; Raymond, K. N.; Toste, F. D. Science 2015, 350, 1235.

(7) (a) Prins, L. J.; Reinhoudt, D. N.; Timmerman, P. Angew. Chem., Int. Ed. 2001, 40, 2382. (b) Sherrington, D. C.; Taskinen, K. A. Chem. Soc. Rev. 2001, 30, 83. (c) Steiner, T. Angew. Chem., Int. Ed. 2002, 41, 48. (d) Slater, A. G.; Perdigão, L. M. A.; Beton, P. H.; Champness, N. R. Acc. Chem. Res. 2014, 47, 3417.

(8) (a) Lehn, J.-M.; Rigault, A.; Siegel, J.; Harrowfield, J.; Chevrier, B.; Moras, D. Proc. Natl. Acad. Sci. U. S. A. 1987, 84, 2565. (b) Drain, C. M.; Lehn, J.-M. J. Chem. Soc., Chem. Commun. 1994, 2313. (c) Fujita, M. Chem. Soc. Rev. 1998, 27, 417. (d) Rapenne, G.; Dietrich-Buchecker, C.; Sauvage, J.-P. J. Am. Chem. Soc. 1999, 121, 994. (e) Collin, J. P.; Dietrich-Buchecker, C.; Gaviña, P.; JimenezMolero, M. C.; Sauvage, J.-P. Acc. Chem. Res. 2001, 34, 477. (f) Fujita, M.; Tominaga, M.; Hori, A.; Therrien, B. Acc. Chem. Res. 2005, 38, 369. (g) Wiester, M. J.; Ulmann, P. A.; Mirkin, C. A. Angew. Chem., Int. Ed. 2011, 50, 114. (h) Chakrabarty, R.; Mukherjee, P. S.; Stang, P. J. Chem. Rev. 2011, 111, 6810. (i) Cook, T. R.; Zheng, Y. R.; Stang, P. J. Chem. Rev. 2013, 113, 734.

(9) (a) Kim, K. Chem. Soc. Rev. 2002, 31, 96. (b) Palmer, L. C.; Stupp, S. I. Acc. Chem. Res. 2008, 41, 1674. (c) Harada, A.; Takashima, Y.; Yamaguchi, H. Chem. Soc. Rev. 2009, 38, 875. (d) Zhang, X.; Wang, C. Chem. Soc. Rev. 2011, 40, 94

(10) (a) Tashiro, K.; Aida, T. Chem. Soc. Rev. 2007, 36, 189. (b) Schneider, H. J. Angew. Chem., Int. Ed. 2009, 48, 3924.

(11) (a) Anelli, P.-L.; Ashton, P. R.; Ballardini, R.; Balzani, V.; Delgado, M.; Gandolfi, M. T.; Goodnow, T. T.; Kaifer, A. E.; Philp, D.; Pietraszkiewicz, M.; Prodi, L.; Reddington, M. V.; Slawin, A. M. Z.; Spencer, N.; Stoddart, J. F.; Vicent, C.; Williams, D. J. J. Am. Chem. Soc. 1992, 114, 193. (b) Claessens, C. G.; Stoddart, J. F. J. Phys. Org. Chem. 1997, 10, 254. (c) Hamilton, D. G.; Sanders, J. K. M.; Davies, J. E.; Clegg, W.; Teat, S. J. Chem. Commun. 1997, 897. (d) Hamilton, D. G.; Davies, J. E.; Prodi, L.; Sanders, J. K. M. Chem. - Eur. J. 1998, 4, 608. (e) Chen, Z. J.; Lohr, A.; Saha-Möller, C. R.; Würthner, F. Chem. Soc. Rev. 2009, 38, 564. (f) Görl, D.; Zhang, X.; Würthner, F. Angew. Chem., Int. Ed. 2012, 51, 6328.

(12) (a) Piguet, C.; Bünzli, J.-C. G. Chem. Soc. Rev. 1999, $28,347$. (b) Davis, J. T.; Spada, G. P. Chem. Soc. Rev. 2007, 36, 296. (c) Faul, C. F. J.; Antonietti, M. Adv. Mater. 2003, 15, 673. (d) Butcher, S. E.; Pyle, A. M. Acc. Chem. Res. 2011, 44, 1302. (e) Watt, M. M.; Collins, M. S.; Johnson, D. W. Acc. Chem. Res. 2013, 46, 955.

(13) (a) Ziganshina, A. Y.; Ko, Y. H.; Jeon, W. S.; Kim, K. Chem. Commun. 2004, 806. (b) Spruell, J. M.; Coskun, A.; Friedman, D. C.; Forgan, R. S.; Sarjeant, A. A.; Trabolsi, A.; Fahrenbach, A. C.; Barin, G.; Paxton, W. F.; Dey, S. K.; Olson, M. A.; Benítez, D.; Tkatchouk, E.; Colvin, M. T.; Carmielli, R.; Caldwell, S. T.; Rosair, G. M.; Hewage, S. G.; Duclairoir, F.; Seymour, J. L.; Slawin, A. M. Z.; Goddard, W. A., III; Wasielewski, M. R.; Cooke, G.; Stoddart, J. F. Nat. Chem. 2010, 2, 870. (c) Norel, L.; Rota, J.-B.; Chamoreau, L.-M.; Pilet, G.; Robert, V.; Train, C. Angew. Chem., Int. Ed. 2011, 50, 7128. (d) Kayahara, E.; Kouyama, T.; Kato, T.; Takaya, H.; Yasuda, N.; Yamago, S. Angew. Chem., Int. Ed. 2013, 52, 13722. (e) Domingo, A.; Vérot, M.; Mota, F.; de Graaf, C.; Novoa, J. J.; Robert, V. Phys. Chem. Chem. Phys. 2013, 15, 6982. (f) Wang, Z.-X.; Zhang, X.; Zhang, Y.-Z.; Li, M.-X.; Zhao, H.; Andruh, M.; Dunbar, K. R. Angew. Chem., Int. Ed. 2014, 53, 11567. (g) Zhang, D.-W.; Tian, J.; Chen, L.; Zhang, L.; Li, Z.-T. Chem. - Asian J. 2015, 10, 56. (h) Mizuno, A.; Shuku, Y.; Suizu, P.; Matsushita, M. M.; Tsuchiizu, M.; Mañeru, D. R.; Illas, F.; Robert, V.; Awaga, K. J. Am. Chem. Soc. 2015, 137, 7612. (i) Ulas, G.; Lemmin, T.; Wu, Y.; Gassner, G. T.; DeGrado, W. F. Nat. Chem. 2016, 8, 354.

(14) (a) Nepogodiev, S. A.; Stoddart, J. F. Chem. Rev. 1998, 98, 1959. (b) Zhang, H.; Zhao, Y. Chem. - Eur. J. 2013, 19, 16862. (c) Kumar, B. V. V. S. P.; Rao, K. V.; Sampath, S.; George, S. J.; Eswaramoorthy, M. Angew. Chem., Int. Ed. 2014, 53, 13073. (d) Chen, L.; Wang, H.; Zhang, D. W.; Zhou, Y. M.; Li, Z.-T. Angew. Chem., Int. Ed. 2015, 54, 4028 . 
(15) (a) Michaelis, L.; Hill, E. S. J. Gen. Physiol. 1933, 16, 859. (b) Michaelis, L. Chem. Rev. 1935, 16, 243. (c) Hünig, S. Pure Appl. Chem. 1967, 15, 109. (d) Bird, C. L.; Kuhn, A. T. Chem. Soc. Rev. 1981, 10, 49. (e) Bockman, T. M.; Kochi, J. K. J. Org. Chem. 1990, 55, 4127.

(16) (a) Nakahara, H.; Wang, J. H. J. Phys. Chem. 1963, 67, 496. (b) Foster, R. Organic Charge-Transfer Complexes; Academic Press: New York, 1969. (c) Monk, P. M. S.; Hodgkinson, N. M.; Partridge, R. D. Dyes Pigm. 1999, 43, 241.

(17) (a) Kosower, E. M.; Cotter, J. L. J. Am. Chem. Soc. 1964, 86, 5524. (b) Evans, A. G.; Evans, J. C.; Baker, M. W. J. Chem. Soc., Perkin Trans. 2 1975, 1310. (c) Bruinink, J.; Kregting, C. G. A.; Ponjeé, J. J. J. Electrochem. Soc. 1977, 124, 1854. (d) Evans, A. G.; Evans, J. C.; Baker, M. W. J. Am. Chem. Soc. 1977, 99, 5882. (e) Bruinink, J.; Kregting, C. G. A. J. Electrochem. Soc. 1978, 125, 1397. (f) Furue, M.; Nozakura, S. Chem. Lett. 1980, 821. (g) Adar, E.; Degani, Y.; Goren, Z.; Willner, I. J. Am. Chem. Soc. 1986, 108, 4696. (h) Yasuda, A.; Mori, H.; Seto, J. J. Appl. Electrochem. 1987, 17, 567. (i) Claude-Montigny, B.; Merlin, A.; Tondre, C. J. Phys. Chem. 1992, 96, 4432.

(18) (a) Kosower, E. M.; Hajdu, J. J. Am. Chem. Soc. 1971, 93, 2534. (b) Geuder, W.; Hünig, S.; Suchy, A. Tetrahedron 1986, 42, 1665.

(19) (a) Jeon, W. S.; Ziganshina, A. Y.; Lee, J. W.; Ko, Y. H.; Kang, J. K.; Lee, C.; Kim, K. Angew. Chem., Int. Ed. 2003, 42, 4097. (b) Jeon, W. S.; Kim, H. J.; Lee, C.; Kim, K. Chem. Commun. 2002, 1828.

(20) (a) Odell, B.; Reddington, M. V.; Slawin, A. M. Z.; Spencer, N.; Stoddart, J. F.; Williams, D. J. Angew. Chem., Int. Ed. Engl. 1988, 27, 1547. (b) Goodnow, T. T.; Reddington, M. V.; Stoddart, J. F.; Kaifer, A. E. J. Am. Chem. Soc. 1991, 113, 4335. (c) Bernardo, A. R.; Stoddart, J. F.; Kaifer, A. E. J. Am. Chem. Soc. 1992, 114, 10624.

(21) (a) Philp, D.; Slawin, A. M. Z.; Spencer, N.; Stoddart, J. F.; Williams, D. J. J. Chem. Soc., Chem. Commun. 1991, 1584. (b) Staley, S. A.; Smith, B. D. Tetrahedron Lett. 1996, 37, 283. (c) Castro, R.; Davidov, P. D.; Kumar, K. A.; Marchand, A. P.; Evanseck, J. D.; Kaifer, A. E. J. Phys. Org. Chem. 1997, 10, 369. (d) Kaminski, G. A.; Jorgensen, W. L. J. Chem. Soc., Perkin Trans. 2 1999, 2, 2365. (e) Nielsen, M. B.; Jeppesen, J. O.; Lau, J.; Lomholt, C.; Damgaard, D.; Jacobsen, J. P.; Becher, J.; Stoddart, J. F. J. Org. Chem. 2001, 66, 3559. (f) Doddi, G.; Ercolani, G.; Mencarelli, P.; Piermattei, A. J. Org. Chem. 2005, 70, 3761. (g) Bria, M.; Cooke, G.; Cooper, A.; Garety, J. F.; Hewage, S. G.; Nutley, M.; Rabani, G.; Woisel, P. Tetrahedron Lett. 2007, 48, 301. (h) Tanabe, K.; Kato, T. Chem. Commun. 2009, 1864. (i) Hansen, S. W.; Stein, P. C.; Sørensen, A.; Share, A. I.; Witlicki, E. H.; Kongsted, J.; Flood, A. H.; Jeppesen, J. O. J. Am. Chem. Soc. 2012, 134, 3857. (j) Frasconi, M.; Fernando, I. R.; Wu, Y. L.; Liu, Z.; Liu, W.-G.; Dyar, S. M.; Barin, G.; Wasielewski, M. R.; Goddard, W. A., III; Stoddart, J. F. J. Am. Chem. Soc. 2015, 137, 11057. (k) Belal, K.; Poitras-Jolicoeur, S.; Lyskawa, J.; Pembouong, G.; Cooke, G.; Woisel, P.; Stoffelbach, F. Chem. Commun. 2016, 52, 1847. Hartlieb, K. J.; Liu, W.-G.; Fahrenbach, A. C.; Blackburn, A. K.; Frasconi, M.; Hafezi, N.; Dey, S. K.; Sarjeant, A. A.; Stern, C. L.; Goddard, W. A., III; Stoddart, J. F. Chem. - Eur. J. 2016, 22, 2736.

(22) Trabolsi, A.; Khashab, N.; Fahrenbach, A. C.; Friedman, D. C.; Colvin, M. T.; Cotí, K. K.; Benítez, D.; Tkatchouk, E.; Olsen, J. C.; Belowich, M. E.; Carmielli, R.; Khatib, H. A.; Goddard, W. A., III; Wasielewski, M. R.; Stoddart, J. F. Nat. Chem. 2010, 2, 42.

(23) Fahrenbach, A. C.; Barnes, J. C.; Lanfranchi, D. A.; Li, H.; Coskun, A.; Gassensmith, J. J.; Liu, Z.; Benítez, D.; Trabolsi, A.; Goddard, W. A., III; Elhabiri, M.; Stoddart, J. F. J. Am. Chem. Soc. 2012, 134, 3061.

(24) Fahrenbach, A. C.; Bruns, C. J.; Cao, D.; Stoddart, J. F. Acc. Chem. Res. 2012, 45, 1581.

(25) Taylor, R. W.; Ara Begum, R.; Day, V. W.; Bowman-James, K. In Cooperativity and the Chelate, Macrocyclic and Cryptate Effects. Supramolecular Chemistry: From Molecules to Nanomaterials; Gale, P. A., Steed, J. W., Eds.; Wiley-VCH: Weinheim, 2012.

(26) (a) Li, H.; Fahrenbach, A. C.; Dey, S. K.; Basu, S.; Trabolsi, A.; Zhu, Z.; Botros, Y. Y.; Stoddart, J. F. Angew. Chem., Int. Ed. 2010, 49, 8260. (b) Li, H.; Zhu, Z.; Fahrenbach, A. C.; Savoie, B. M.; Ke, C. F.; Barnes, J. C.; Lei, J. Y.; Zhao, Y.; Lilley, L. M.; Marks, T. J.; Ratner, M.
A.; Stoddart, J. F. J. Am. Chem. Soc. 2013, 135, 456. (c) McGonigal, P. R.; Deria, P.; Hod, I.; Moghadam, P. Z.; Avestro, A. J.; Horwitz, N. E.; Gibbs-Hall, I. C.; Blackburn, A. K.; Chen, D. Y.; Botros, Y. Y.; Wasielewski, M. R.; Snurr, R. Q.; Hupp, J. T.; Farha, O. K.; Stoddart, J. F. Proc. Natl. Acad. Sci. U. S. A. 2015, 112, 11161.

(27) (a) Barnes, J. C.; Fahrenbach, A. C.; Cao, D.; Dyar, S. M.; Frasconi, M.; Giesener, M. A.; Benítez, D.; Tkatchouk, E.; Chernyashevskyy, O.; Shin, W. H.; Li, H.; Sampath, S.; Stern, C. L.; Sarjeant, A. A.; Hartlieb, K. J.; Liu, Z.; Carmieli, R.; Botros, Y. Y.; Choi, J. W.; Slawin, A. M. Z.; Ketterson, J. B.; Wasielewski, M. R.; Goddard, W. A., III; Stoddart, J. F. Science 2013, 339, 429. (b) Gibbs-Hall, I. C.; Vermeulen, N. A.; Dale, E. J.; Henkelis, J. J.; Blackburn, A. K.; Barnes, J. C.; Stoddart, J. F. J. Am. Chem. Soc. 2015, 137, 15640.

(28) (a) Wang, Y.; Frasconi, M.; Liu, W.-G.; Liu, Z.; Sarjeant, A. A.; Nassar, M. S.; Botros, Y. Y.; Goddard, W. A., III; Stoddart, J. F. J. Am. Chem. Soc. 2015, 137, 876. (b) Wang, Y.; Frasconi, M.; Liu, W.-G.; Sun, J.; Wu, Y.; Nassar, M. S.; Botros, Y. Y.; Goddard, W. A., III; Wasielewski, M. R.; Stoddart, J. F. ACS Cent. Sci. 2016, 2, 89.

(29) (a) Bruns, C. J.; Frasconi, M.; Iehl, J.; Hartlieb, K. J.; Schneebeli, S. T.; Cheng, C.; Stupp, S. I.; Stoddart, J. F. J. Am. Chem. Soc. 2014, 136, 4714. (b) Bruns, C. J.; Stoddart, J. F. Acc. Chem. Res. 2014, 47, 2186.

(30) (a) Li, H.; Fahrenbach, A. C.; Coskun, A.; Zhu, Z.; Barin, G.; Zhao, Y.; Botros, Y. Y.; Sauvage, J.-P.; Stoddart, J. F. Angew. Chem., Int. Ed. 2011, 50, 6782. (b) Zhu, Z.; Fahrenbach, A. C.; Li, H.; Barnes, J. C.; Liu, Z.; Dyar, S. M.; Zhang, H.; Lei, J. Y.; Carmieli, R.; Sarjeant, A. A.; Stern, C. L.; Wasielewski, M. R.; Stoddart, J. F. J. Am. Chem. Soc. 2012, 134, 11709. (c) Fahrenbach, A. C.; Zhu, Z.; Cao, D.; Liu, W.-G.; Li, H.; Dey, S. K.; Basu, S.; Trabolsi, A.; Botros, Y. Y.; Goddard, W. A., III; Stoddart, J. F. J. Am. Chem. Soc. 2012, 134, 16275. (d) Witus, L. S.; Hartlieb, K. J.; Wang, Y.; Prokofjevs, A.; Frasconi, M.; Barnes, J. C.; Dale, E. J.; Fahrenbach, A. C.; Stoddart, J. F. Org. Biomol. Chem. 2014, 12, 6089. (e) Sun, J. L.; Wu, Y. L.; Liu, Z.; Cao, D.; Wang, Y.; Cheng, C.; Chen, D. Y.; Wasielewski, M. R.; Stoddart, J. F. J. Phys. Chem. A 2015, 119, 6317. (f) Sun, J. L.; Wu, Y. L.; Wang, Y.; Liu, Z.; Cheng, C.; Hartlieb, K. J.; Wasielewski, M. R.; Stoddart, J. F. J. Am. Chem. Soc. 2015, 137, 13484.

(31) (a) Cheng, C.; McGonigal, P. R.; Liu, W.-G.; Li, H.; Vermeulen, N. A.; Ke, C. F.; Frasconi, M.; Stern, C. L.; Goddard, W. A., III; Stoddart, J. F. J. Am. Chem. Soc. 2014, 136, 14702. (b) Cheng, C.; Stoddart, J. F. ChemPhysChem 2016, DOI: 10.1002/cphc.201501155.

(32) (a) Cheng, C.; McGonigal, P. R.; Schneebeli, S. T.; Li, H.; Vermeulen, N. A.; Ke, C. F.; Stoddart, J. F. Nat. Nanotechnol. 2015, 10, 547. (b) Cheng, C.; McGonigal, P. R.; Stoddart, J. F.; Astumian, R. D. ACS Nano 2015, 9, 8672.

(33) Fahrenbach, A. C.; Sampath, S.; Late, D. J.; Barnes, J. C.; Kleinman, S. L.; Valley, N.; Hartlieb, K. J.; Liu, Z.; Dravid, V. P.; Schatz, G. C.; Van Duyne, R. P.; Stoddart, J. F. ACS Nano 2012, 6, 9964.

(34) (a) Li, H.; Zhao, Y.; Fahrenbach, A. C.; Kim, S. Y.; Paxton, W. F.; Stoddart, J. F. Org. Biomol. Chem. 2011, 9, 2240. (b) Hmadeh, M.; Fahrenbach, A. C.; Basu, S.; Trabolsi, A.; Benítez, D.; Li, H.; AlbrechtGary, A.-M.; Elhabiri, M.; Stoddart, J. F. Chem. - Eur. J. 2011, 17, 6076. (c) Li, H.; Cheng, C.; McGonigal, P. R.; Fahrenbach, A. C.; Frasconi, M.; Liu, W.-G.; Zhu, Z.; Zhao, Y.; Ke, C. F.; Lei, J. Y.; Young, R. M.; Dyar, S. M.; Co, D. T.; Yang, Y. W.; Botros, Y. Y.; Goddard, W. A., III; Wasielewski, M. R.; Astumian, R. D.; Stoddart, J. F. J. Am. Chem. Soc. 2013, 135, 18609.

(35) Olson, M. A.; Botros, Y. Y.; Stoddart, J. F. Pure Appl. Chem. 2010, 82, 1569

(36) Nishio, M.; Umezawa, Y.; Honda, K.; Tsuboyama, S.; Suezawa, H. CrystEngComm 2009, 11, 1757.

(37) Andersen, S. S.; Share, A. I.; Poulsen, B. L. C.; Kørner, M.; Duedal, T.; Benson, C. R.; Hansen, S. W.; Jeppesen, J. O.; Flood, A. H. J. Am. Chem. Soc. 2014, 136, 6373.

(38) Barnes, J. C.; Juricek, M.; Vermeulen, N. A.; Dale, E. J.; Stoddart, J. F. J. Org. Chem. 2013, 78, 11962.

(39) Wu, S. F.; Ma, X. Tetrahedron Lett. 2011, 52, 5960. 
(40) (a) Zhao, Y.; Truhlar, D. G. Theor. Chem. Acc. 2008, 120, 215.

(b) Zhao, Y.; Truhlar, D. G. Acc. Chem. Res. 2008, 41, 157.

(41) (a) Clark, T.; Chandrasekhar, J.; Spitznagel, G. W.; Schleyer, P. V. R. J. Comput. Chem. 1983, 4, 294. (b) Frisch, M. J.; Pople, J. A.; Binkley, J. S. J. Chem. Phys. 1984, 80, 3265. (c) Krishnan, R.; Binkley, J. S.; Seeger, R.; Pople, J. A. J. Chem. Phys. 1980, 72, 650. (d) McLean, A. D.; Chandler, G. S. J. Chem. Phys. 1980, 72, 5639.

(42) (a) Grimme, S.; Antony, J.; Ehrlich, S.; Krieg, H. J. Chem. Phys. 2010, 132, 154104. (b) Goerigk, L.; Grimme, S. Phys. Chem. Chem. Phys. 2011, 13, 6670.

(43) (a) Tannor, D. J.; Marten, B.; Murphy, R.; Friesner, R. A.; Sitkoff, D.; Nicholls, A.; Honig, B.; Ringnalda, M.; Goddard, W. A., III. J. Am. Chem. Soc. 1994, 116, 11875. (b) Marten, B.; Kim, K.; Cortis, C.; Friesner, R. A.; Murphy, R. B.; Ringnalda, M. N.; Sitkoff, D.; Honig, B. J. Phys. Chem. 1996, 100, 11775.

(44) Jaguar, version 8.2; Schrödinger, LLC: New York, 2013.

(45) Boys, S. F.; Bernardi, F. Mol. Phys. 1970, 19, 553.

(46) Stewart, J. J. P. J. Mol. Model. 2013, 19, 1.

(47) Stewart, J. J. P. MOPAC2012; Stewart Computational Chemistry: Colorado Springs, CO, 2012; http://openmopac.net.

(48) Wertz, D. H. J. Am. Chem. Soc. 1980, 102, 5316. 